\title{
Aristotle on the Logos of the Craftsman
}

(Phronesis, forthcoming)

Thomas Kjeller Johansen

Department of Philosophy, Classics, History of Art and Ideas, University of Oslo, PO Box 1020, Blindern, 0315 OSLO. Norway

t.k.johansen@ifikk.uio.no

\begin{abstract}
Aristotle thinks that an account, a logos, of some sort, is characteristic of craft, techne. Some scholars think that the logos element of techne is tagged onto experience as a theoretical element not directly engaged in successful production: I argue instead that the logos grounds the productive ability of craft, and also that is practically orientated in a way that distinguishes it from the logos of theoretical science. Understanding the logos of craft thus helps us explain how the craftsman differs both from the merely experienced practitioner and from the theoretical scientist.
\end{abstract}

\section{Keywords}

Aristotle; craft; logos; experience; theoretical knowledge; necessity

\section{Introduction}

It is clear from several places in Aristotle that he thinks that an account, a logos of some sort is important to craft, techne. ${ }^{1}$ However, just what the relationship of techne to logos is, and what kind of logos is involved is far from clear. The question I am particularly interested in here is what role, if any, the logos plays in ensuring practical success for the craftsman. Aristotle says that technē presupposes experience, but also that experience on its own may produce successful results. This leaves the possibility that the logos element of techne is tagged onto experience, as an element that is not directly engaged in ensuring successful production, however important the logos may be to other features of craft, such as the craftsman's ability to account for his actions and to teach. On this picture craft would appear to be a joint practical-theoretical undertaking: experience ensuring practical success, the logos shoring up craft's theoretical credentials. This paper tries to show that this picture is misleading. ${ }^{2}$ 
I shall look at three texts in particular. The first is Nicomachean Ethics $(E N) 6.4$ which is the closest thing we have to a definition of craft in Aristotle; the second is Metaphysics (Metaph.) A.l (referring back to EN 6), which distinguishes techne from experience in terms of the logos that craft possesses, ${ }^{3}$ and the last is Metaph. $\Theta .2$, which explains the role the logos plays in techne's being a capacity to bring about certain results. I shall argue that these texts together show how the logos grounds the productive ability of craft. The logos is not a theoretical adjunct to experience but rather part of what makes the craft able to produce. Indeed, the logos renders the craftsman practically superior to the merely experienced. The logos is practically orientated in a way that also distinguishes it from the logos of theoretical science. Understanding the logos of craft helps us explain, then, how the craftsman differs both from the merely experienced practitioner and from theoretical scientist.

\section{The account of technē in $E N 6.4$}

T1 What admits of being otherwise includes what is produced and what is achieved in action. Production and action are different; about them we rely also on [our] popular distinctions. And so the state involving an account (logos) and concerned with action is different from the state involving an account and concerned with production. Nor is one included in the other; for action is not production, and production is not action. Now building, for instance, is a craft, and is essentially a certain state involving an account concerned with production; there is no craft that is not a state involving an account concerned with production, and no such state that is not a craft. Hence a craft is the same as a state involving a true account concerned with production. Every craft is concerned with coming to be, and the exercise of the craft is also considering (theōrein) ${ }^{4}$ how something that admits of being and not being comes to be, something whose principle is in the producer and not in the product. For a craft is not concerned with things that are or come to be by necessity; nor with things that are by nature, since these have their principle in themselves. Since production and action are different, craft must be concerned with production, not with action. In a way craft and fortune are concerned with the same things, as Agathon says: 'Craft was fond of fortune, and fortune of craft.' A craft, then, as we have said, is a state involving true reason concerned with production. Lack of craft is the contrary state involving false reason and concerned with production. Both are concerned with what admits of being otherwise. ${ }^{5}$ 
Aristotle uses a formula for identifying craft familiar from other contexts: 'If nothing other than $\mathrm{X}$ is $\mathrm{Y}$ and everything $\mathrm{Y}$ is $\mathrm{X}$, then $\mathrm{X}$ is the same as $\mathrm{Y} .{ }^{6}{ }^{6}$ The formula can strictly only establish coextensiveness, which in itself is insufficient for an Aristotelian essential definition. However, the passage suggests that Aristotle is aiming at what craft is as such when he says that building as a craft 'is essentially (hoper) a certain state involving an account concerned with production'. One reason why he thinks that a definition of craft is on the cards may be that he is accounting for craft as a state of reason concerned with a certain kind of object. For this was Aristotle's favoured method of defining the capacities and states of the soul in the $D A$ (esp. 2.4). He may then take it that the formula as applied to an $\mathrm{X}$ and an $\mathrm{Y}$ where $\mathrm{Y}$ counts as a proper object of $\mathrm{X}$ will help render an essential definition of $\mathrm{X}$.

This in turn raises the question, which I shall return to towards the end of this paper, whether the defining object should be understood not just as formal cause, as is typically the case when Aristotle defines our cognitive powers in the $D A$, but also as final cause, as that for the sake of which the craft is. However this may be, Aristotle clearly does use the relationship of states and capacities to their objects to distinguish them. So he distinguishes craft by its proper object from other cognitive achievements in two steps. First, he differentiates craft knowledge together with practical knowledge from theoretical knowledge: theoretical knowledge is concerned with what is necessary, the other two with what is contingent, what may or may not come to be. Secondly, he distinguishes craft from practical knowledge by a further difference: craft is concerned with what can be made (to poietton), practical knowledge with what can be done (to prakton). The result can be set out in a tree diagram:

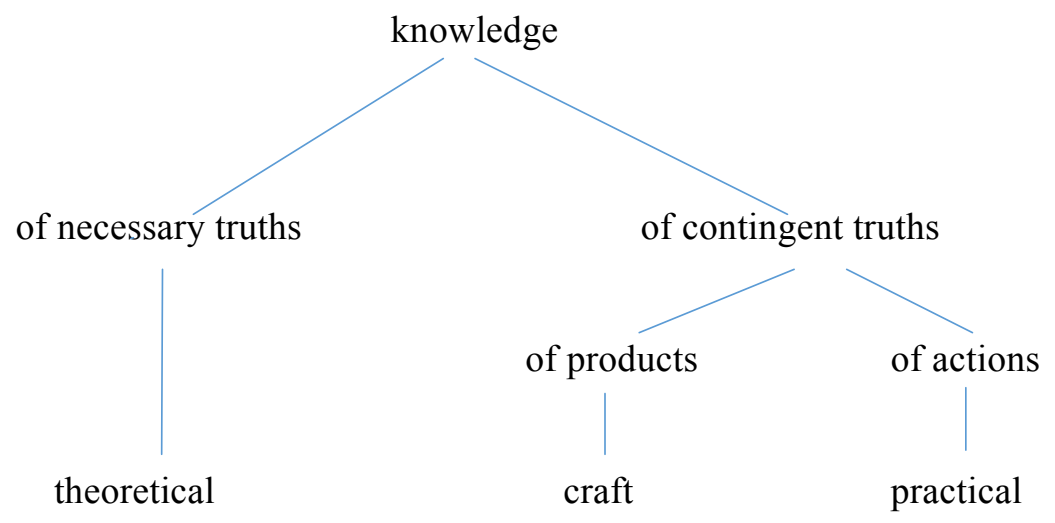

Let me make a few preliminary notes about $\mathrm{T} 1$, which will set the stage for the discussion of the Metaph. 
(1) Technē comes with (meta) a true logos. Logos can be and has been understood here as the rational capacity (reason), or as reasoning or as an account. ${ }^{7}$ Each of these is justifiable at different points in Aristotle's discussion in EN 6, and it is sensible to understand them generally as nonexclusive options. 'Capacity' is a natural reading in Ch. 2, where Aristotle is discussing the part of the soul that has $\log o s$ as opposed to the parts, like nutrition, which are without $\log \operatorname{los}(\operatorname{alog} a){ }^{9}$ However, Aristotle also refers to exercises of logos. For example, in his references to choice (proairesis), he mentions the true logos that goes together with correct desire (1139a24) or the logos for the sake of something (logos ho heneka tinos, 1139a32-3). Here it is natural to think of the logos as the reasoning which works with desire to bring about an action. And when the logos is referred to as true it makes sense to think of this not as a capacity that is always right - after all we are capable of making rational mistakes - but as the correct exercise of reason. What it means to be reasoning correctly here - that is, in the context of having knowledge in its various forms - is to assert or deny correctly. So we are naturally led to understanding the logos in terms of the proposition being affirmed or negated, the proposition which is the content of a certain reasoning. The truth of the reasoning would be a function of the truth of the proposition affirmed or denied.

What would be the content of this logos? In practical knowledge the logos, as we saw, is for the sake of an end. More specifically, the logos represents the deliberation about how to realise this end. A true logos, then, would express correctly how to achieve a certain practical goal. Aristotle elsewhere (e.g. $E N$ 1112b11-16) assimilates practical reasoning and productive reasoning: you start from the end and reason about the means to bring it about until you arrive at either what is doable now. Correspondingly, the logos involved in techne would say how to bring about a certain product. This suggestion seems confirmed when Aristotle in T1 says that technē considers (theōrein) 'how something that admits of being and not being comes to be'. The true logos involved in craft will represent correct reasoning about the means that brings about a certain product.

It is clear, however, that such a logos can be understood at different levels of generality, from a very general description of how to make a kind of product (e.g. 'to make a cake, mix together equal measures of flour, milk, sugar and butter') to very specific instructions about a particular instance of this kind (e.g. 'when making this spaghetti Bolognese, avoid pepper, which irritates John's stomach). Aristotle suggests in several places that productive knowledge, like practical wisdom, deals with the particular. ${ }^{10}$ So we might expect the logos to tend towards containing information sufficiently specific to direct the craftsman to the production of particular outcomes. However, the logos of the techne in T1 cannot be too specific since it goes with a state 
(hexis) which is a general disposition to act. So the logos has to cover a range of possible scenarios. Compare the virtuous hexis of a man's character, his general ability to act virtuously. If the craftsman similarly possesses the hexis even when he is not exercising it on a particular occasion, but is in a state such that he could be productive on a variety of occasions, then presumably his logos is not just an account of a particular product. This is of course consistent with saying that when the craftsman exercises the craft the logos will be adapted to particular circumstances. But then we are not talking about the craft as a hexis but as actualised. ${ }^{11}$

The suggestion is, then, that we in $\mathrm{T} 1$ take the $\log o$ s to be an account, which will give information about how to bring about a kind of product at some level of generality and in a manner that can be adapted to different particular circumstances. More will be said about this in the Metaphysics.

(2) Aristotle has in mind in T1 a division of states of reason not just as different but also as discrete or non-overlapping. So he emphasises, for example, that neither productive knowledge nor practical wisdom is contained in one another. Craft is a state of intellect that deals with what is makeable (poiēton) and so is actualised in production, while practical knowledge is a state dealing with what is doable (prakton) and so is actualised in action (praxis). Both contrast with theoretical knowledge in dealing with the contingent, what may or not come into being. Since theoretical knowledge (epistèmēe) proper is of necessary truths, we cannot understand technē as epistēmē in that sense. Yet Aristotle elsewhere refers to technē as an poietike epistēme.$^{12}$ The diagram is then not misleading in implying a more generic or looser notion of epistēme under which both theoretical knowledge and craft fall. However, the divisions still leave us with the impression that theoretical knowledge and craft will be discrete. ${ }^{13}$ Therefore, we might think the logos of the craftsman will not overlap with that of the theoretician either, if theōria concerns just eternal and necessary truths while productive knowledge concerns the contingent alone.

However, there are two distinctions involved in the contrast between productive and theoretical knowledge. T1 mentions just the one between the contingent and the necessary. But, as we shall see, Aristotle also uses the distinction between the universal and the particular to distinguish the two kinds of knowledge. So in EN 6.6 Aristotle writes that 'scientific knowledge is supposition about universals, things that are by necessity', as if being of the universal as well as of the necessary was characteristic of such knowledge. In $E N 1.6$ he said that the doctor does not study health as such but human health to the point of the health of this human, for it is individuals he cures (1097a10-15). So one might well gain the impression that craft deals with the particular and 
contingent only, while epistēme confines itself to the universal and contingent. However, it is important to note that Aristotle in EN 6.7 (1141b15-23) does not distinguish between practical knowledge and theoretical knowledge by saying that the former is of the particular and the latter of the universal but by saying that the former is not just of the universal but also of particulars. $\mathrm{He}$ suggests that it is experience that gives one knowledge of particulars. Since practical and productive knowledge are analogous in this respect - indeed Aristotle in 6.7 uses a medical example to make his point about practical knowledge - the suggestion is that productive knowledge too will be of both the universal and the particular.

If one analyses craft in terms of experience and logos, as does Metaph. A.1, and if experience is of the particular, as EN 6.7 suggests, then it would seem to be especially the logos element of craft that relates it to the universal. However, if the logos of craft tends towards the universal, how do we avoid blurring the distinction between theoretical epistemme and craft? How do we maintain the discreteness of the two, if craft's logos deals with something also dealt with by scientific knowledge? And if the logos is general, how would it ground an ability to produce particular outcomes? These are questions that I shall pursue in the Metaphysics.

(3) What does it mean to say that craft is a productive state 'with' (meta) a logos? 'With' can involve different kinds of togetherness from mere conjunction to union. So one might think of techne as having two discrete components: a productive state or ability plus the possession of an account of what one is doing, or one might think of the two as integrated in various ways so that one could not have the productive ability without the account. ${ }^{14}$ Again this second kind of view might come in different forms. For example, the possession of the account could be a mere necessary condition (as gravity is a necessary condition of playing football) or the account could be something that directly grounds or explains the state (as knowing the rules is a necessary condition of playing football).

A passage in EN $6.13(1144 \mathrm{~b} 17-30)$ where Aristotle returns to the claim that 'virtue is a state with the right account' (1144b27) supports the second option. Here he lines up three views of the relationship between practical wisdom and virtue depending on the role given to orthos logos. There is the Socratic view that identifies virtue and practical wisdom, presumably on the thought that the possession of a correct account is sufficient for being virtuous. There is also the common view that virtue is in accordance with $(k a t a)$ the correct account. This is too weak for the reason, it seems, that somebody can act in accordance with the correct account without knowingly doing so, in which case he is hardly virtuous. Finally, there is Aristotle's intermediary view that virtue is 
'with' (meta) the correct account, where this, to contrast with the second case, must mean that the virtuous agent acts virtuously because of the account that he possesses. ${ }^{15}$ That is to say, to be not just 'in accordance' with the right account but 'with' the right account, the account must be involved in a way that explains how or why the agent acts correctly. In techne, similarly, the productive state would be 'with' an account in that the craftsman is able to produce the right product, at least in part, because he possesses a true account. ${ }^{16}$ Again this suggestion and the manner in which the true account might ground the productive ability will be further clarified in the Metaph., to which I now turn.

\section{Logos in Metaphysics A.1}

T2 All human beings by nature desire to know. A sign of this is their love of the senses. For even apart from their usefulness, they are cherished for themselves, and more than any others the sense that operates through the eyes. For we choose seeing not just with a view to acting but even when we are not intending to act above almost all other things. The reason is that among the senses this most of all makes us know things, showing us many differences.

Animals come to be, possessing perception by nature. In some of them memory does not come about from perception, while for others it does. And that is why they are wiser or better at learning than the ones that are not capable of remembering. Wise without learning are those that are not able to hear sounds (for example the bee and if there is any other such kind of animal), while those learn which in addition to memory also have this sense. Some further animals live by means of imagining and remembering things, and have little by way of experience. Human kind, however, live by craft and reasoning.

Human beings acquire experience from memory, for many memories of the same thing constitute the power of a single experience. Indeed, experience seems to be similar almost to knowledge and craft, and knowledge and craft come about through experience in humans.

For experience produces craft, as Polus rightly says, and inexperience chance. ${ }^{17} \mathrm{Craft}$ comes about whenever from many thoughts belonging to experience arises a single universal judgement about similar things. For having the judgement that this thing here helped Callias when he was suffering from this here disease and Socrates too and that it in this way in each case helped many is a matter of experience. But it is proper to craft to judge that this helped all such people differentiated as a single kind suffering from this here disease, for example to the phlegmatic or bilious when they are burning with fever. For the purposes of acting 
experience does not seem to differ from craft; but we see the experienced being rather more successful than those who possess an account without experience. (The reason is that experience is cognition of particulars, while craft is of universals, and actions and processes of coming into being are concerned with the particular. For the doctor does not cure human being, except coincidentally, but Callias or Socrates or one of the others that are referred to in this way with which being a human being coincides.)

Still we think that knowing and understanding belong more to craft than to experience, and we take the craftsmen to be wiser than the experienced, on the assumption that wisdom follows in all cases ${ }^{18}$ on the basis of knowledge. This is because some people know the cause but others do not. For the experienced know the "that", but do not know why, while the others know the "why" and the cause. That is why in each case we think the architects are more honourable and more knowledgeable than the manual workers, and wiser, because they know the causes of the things that are being made $<$ but the others - just as certain soulless beings make things not knowing what they make, as for example fire burns, so, while the soulless beings make each of these things because of their particular nature, the manual workers do so by habit $>;{ }^{19}$ [the architects] we think are wiser not because they are practical but because they themselves possess the account and know the causes. Generally, being able to teach is a sign of who knows and who does not, and because of this we think that craft more than experience is knowledge. For [the craftsmen] are capable of teaching, while the others are not. ${ }^{20}$

The first chapter of the Metaph. prepares the reader for the characterisation of wisdom (sophia) in Ch. 2. Aristotle starts famously by saying that all human beings desire to know. He then considers different kinds of cognition (gnōsis) - perception, memory, experience, craft, theoretical knowledge - as steps in a progression towards wisdom. The progression may be understood as a ranking of different kinds of cognition: by the criteria of wisdom craft, say, ranks more highly than experience. But the progression may also be understood developmentally in those beings that have the relevant capacities. ${ }^{21}$ So perception leads to memory which leads to experience, which in humans may bring about craft or to theoretical knowledge. ${ }^{22}$

While the criteria of wisdom will not be spelled out until Ch. 2 it is important to underline how the ranking already in the first chapter serves as the basis for the characterisation of wisdom. For it is the characteristics that matter from the point of view of wisdom that generate the ranking. Here they are in brief. Wisdom is: 
1. cognisant of the cause, including the end;

2. cognisant of the universal;

3. able to teach;

4. directive ('architectonic');

5. accurate (akribes);

6. pursued for its own sake (rather than its consequences).

A couple of examples of how the criteria shape the ranking. Aristotle acknowledges that perception is the most authoritative cognition when it comes to particulars. Still perception is only at Level 1 in the ranking since wisdom is to do with what is most universal. Similarly, for practical purposes experience may often be as good as or better than theoretical cognition. Indeed, he says that we tend to think of people as wise exactly when their knowledge is practically useless. Yet he takes the craft and science to be superior to experience because they grasp the universal and the cause. Aristotle suggests, then, other possible rankings; this is a ranking of sorts of cognition with respect to wisdom.

This point in turn raises the possibility of a certain kind of bias or selectiveness in Aristotle's presentation of the kinds of cognition. And indeed one may suspect Aristotle of exaggerating the theoretical aspects of craft because he wants to present it as leading up to theoretical knowledge. This point can be made in comparison with our modern notions of craft. So Reeve observes: 'We tend to put more emphasis on a craftsman's ability to produce high-quality products than on his ability to explain what he does. Aristotle, by contrast, thinks that the most excellent, most virtuous, or wisest craftsman are those who possess what we would most naturally consider to be theoretical knowledge. ${ }^{23}$ Or the point can be made as an internal criticism of Aristotle: in the $E N$ Aristotle offers a sharper distinction, as we saw, between theoretical and productive knowledge in terms of their modally discrete objects, whereas in Metaph.A.1 this modal distinction is absent. Rather, craft in grasping the cause and the universal seems to fall on the side of theōria. If there is an inconsistency between the two works it would be surprising, since Aristotle (assuming it is he) at the end of Metaph.A.1 refers us to the Ethics. But just how, if at all, the two texts are consistent is not obvious.

\section{Craft vs. experience}


The suggestion in T2 seems to be that craft deals with the universal and experience with the particular (Callias, Socrates and so forth). But this is too quick. On the one hand, craft deals with the particular as well as the universal, as Aristotle acknowledges when he says that the doctor cures the particular patient (981a18-20), where he clearly has in mind the doctor as such since the doctor's relationship to the patient as a universal, 'man', is said in contrast to be accidental. This cannot mean that the craft deals with one particular, Socrates. A craft that occupied itself only with one individual would be otiose, and even experience is extendable to new cases. Rather Aristotle's point must be that the doctor's knowledge, as a craft, is realised in relation to particulars, since it is particulars who are cured. This does not exclude the craft's having general scope, it just means that it is a general ability to deal with particular cases. One's theoretical knowledge in contrast is realised just in relation to a universal; even if particulars may provide the occasion for exercising one's theoretical knowledge the knowledge exercised is not about them.

On the other side of the contrast, the experienced person appears to rely on a general concept of some sort when collecting and organising his memories. ${ }^{24}$ For Aristotle says: 'for many memories of the same thing constitute the power of a single experience' (980b30). Here it seems that 'the same thing' (tou autou pragmatos) must refer not to a particular individual but a kind of thing or state of affairs. ${ }^{25}$ For, as the medical example shows, Aristotle has in mind cases where many different individuals are observed as having the same kind of property. So experience judges 'that this thing here helped Callias when he was suffering from this here disease and Socrates too and that it in this way in each case helped many' (981a8-9). The emphasis accordingly is on the plurality of observations which have been unified in one judgement. Experience seems then to involve having some general concept of what one is experiencing. ${ }^{26}$ We cannot draw the line between experience and craft simply in terms of one dealing with the particular, the other with the universal. When Aristotle says in T1 that 'experience is cognition of particulars, while craft is of universals' (981a15-16) it is better to take him to mean not that experience is exclusively concerned with particulars and craft exclusively with universals.

How the experienced person's concept falls short of that of the craftsman is made clearer when Aristotle says 'it is proper to craft to judge that this helped all such people differentiated as a single kind suffering from this here disease, for example to the phlegmatic or bilious when they are burning with fever' (981a10-12). We might have thought that the craftsman differed from the experienced person merely by the fact of grasping $a$ universal. However, here we see that the universal is not just that, but one that differentiates the cases as being instances of a specific kind of disease or condition, ${ }^{27}$ such as being phlegmatic or bilious. These are importantly not just 
symptomatic terms but, in the context of Hippocratic medicine, assumed for the sake of argument, diagnostic terms. Diagnosing the patient as bilious will tell the doctor what is wrong the patient and give the cause of the disease, too much bile. It will also give him an indication of the appropriate cure. So the doctor will, given the diagnosis, understand why the medicine worked, not just which medicine it was, something the merely experienced person could also have told you.

Later in the chapter (981a23-5) Aristotle says that experience grasps the fact or 'the that' and craft the cause or 'the why'. This makes good sense on the current reading. For the experienced person has grasped that this medicine helps people suffering in such and such a way, while the doctor has understood why that is so. There is a strong parallel with Aristotle's use of the distinction between knowing that and knowing why in the Posterior Analytics (APo). The parallel is no doubt deliberate, heightening, as it does, the impression of technē as being like scientific knowledge, and so closer to theōria. In $A P o$, Aristotle tells us, we start a scientific enquiry knowing that there is an eclipse and then ask why there is an eclipse. Here, as in T1, Aristotle uses the 'pragma' for the fact or state of affairs to be explained in demonstration. ${ }^{28}$ When the person enquires into why there is an eclipse, we assume that he already has some sort of concept of an eclipse, temporary obscuration of a planet, say, just not the concept that states why there is an eclipse, which will be explained by its essence. The experienced person when informed of the true nature of the eclipse does not come to learn that what he was observing was an eclipse, but what the eclipse that he rightly took himself to be observing really is. Similarly, the experienced person has some concept of the disease he observes in the various cases, as he does of the medicine, but not the concept that explains what it is he is observing, what it is about the disease and the medicine that makes the one respond to the other. $^{29}$

If the experienced has a general notion of the disease and a concept of the medicine, just not a notion of the universal cause, how can Aristotle also claim in $\mathrm{T} 2$ that 'that experience is cognition of particulars, while craft is of universals'? Say that the experienced person has grasped that Callias, Socrates and Hermogenes all suffered from 'this here disease'. When asked what 'this here disease' is, he answers pointing to a range of symptoms, observable to perception: red spots and fever. He may even give the disease a name, referring to what he can observe, such as 'chickenpox'. When asked what 'this here medicine' is which in his experience has brought about relief, he may say 'brown vinegar' or 'honey'. If he comes across another case of chickenpox he will know to prescribe brown vinegar. However, if you ask him 'Why?', all he can say is that it worked for Callias, Socrates and Hermogenes. He has no causal story to tell about why vinegar works against chickenpox. Nor if you ask him why he thinks that this is a case of chickenpox can he say other 
than that this person displays the same symptoms as Callias, Socrates and Hermogenes. So in terms of justifying both his diagnosis and his treatment the experienced person will refer back to individual cases that he has observed in the past. He is limited by the information provided by those individual cases. The experienced person has no basis on which to discriminate features of the cases that are merely accidental to the pathology and those that are essential to it. If a patient presented himself who lacked one or more of the symptoms of the previous cases it would for the experienced person ipso facto count against diagnosing the same disease, even if those symptoms were not really relevant to the disease. Contrast the doctor: her grasp of the universal cause of chickenpox (varicella zoster virus) allows her to diagnose the disease on the basis of her grasp of the essential features of the disease, not just the particular symptoms of particular past cases, and it allows her to justify why this medicine will work (or not) in relation to this patient's condition. So while the experienced person may have a grasp of a universal, 'chickenpox' or 'vinegar', Aristotle can still maintain that he is concerned with particulars since the experienced person's understanding of what the disease is and its treatment is based on particular cases. ${ }^{30}$ There is no contradiction between saying that the experienced grasps a universal and that his experience is concerned with particulars, if his universal is merely an extrapolation from particular cases.

In the $E N$ Aristotle makes a germane point about the difference between the merely experienced and the knower:

T3 Nor is prudence about universals only. It must also acquire knowledge of particulars, since it is concerned with action and action is about particulars. That is why in other areas also some people who lack knowledge but have experience are better in action than others who have knowledge. For someone who knows that light meats are digestible and [hence] healthy, but not which sorts of meats are light, will not produce health; the one who knows that bird meats are light [and healthy $]^{31}$ will be better at producing health. And since prudence is concerned with action, it must possess both [the universal and the particular knowledge] or the [particular] more [than the universal]. Here too, however, [as in medicine] there is a ruling [science].' (EN 1141b15-23, tr. Irwin)

Here Aristotle uses an example from craft, specifically medicine, to illustrate a point about prudence. As in Metaph. A.1, he suggests that the merely experienced person is sometimes more effective than the one who just knows the universal. But note again that the universal that the experienced person does not know is the causally pertinent one: that the meat is digestible. ${ }^{32}$ The 
experienced man knows that chicken generally (not just this or that piece of chicken) is wholesome but not from the point of view of its being digestible, the cause of its being wholesome (or light). ${ }^{33}$

\section{Logos without experience}

The difference between experience and craft appears to be the logos. One might think here of the $\log o s$ as the differentia of craft: craft is a certain kind of experience, the one characterised by logos. If so, one might also suppose that one can only have the logos if one has the experience. However, in T2 Aristotle presents the logos as if it is an element one can acquire without the experience. And he seems to suggest that the experience is sufficient for the productive capacity when he says: 'For the purposes of acting experience seems not to differ from craft but we see the experienced being rather more successful than those who possess an account without experience' (981a12-15). Similarly, as we just saw, he also says in the $E N$ (T3) that the experienced is more successful than the one who just knows the universal. In the context of Metaph A.1, however, the claim is puzzling because Aristotle has apparently just presented the previous cognitive states as a precondition for the subsequent: from perception arises memory, from memory experience, and so presumably also from experience craft. If experience precedes craft, and having the logos is characteristic of craft, how is it possible for the craftsman to know the logos without having the relevant experience?

Alexander's solution, followed by some modern scholars, ${ }^{34}$ is to distinguish between two ways of acquiring the logos: one through experience, which was how the craft was first developed, and another way through teaching, which works now that the craft has been invented. Because we now have teachers we can learn medical accounts without ourselves having medical experience. But the craft as such arose from experience. Or as Polus put it in Gorgias 449c, the passage Aristotle averts to in Metaph. A.1 (translation by Zeyl):

Many among men are the crafts experientially devised by experience, Chaerephon. Yes, it is experience that causes our times to march along the way of craft, whereas inexperience causes them to march along the way of chance.

We might then put the situation like this: while experience is presupposed by the existence of the craft, experience is not presupposed by somebody's possession of the logos. Granted this reading, it may be agreed that you can entertain the logos without having the experience. But does that mean that one can also possess the craft without experience? 
As a reason to say 'no', one might think that the case of the inexperienced knower is exactly a case of failing to possess the productive hexis, as EN termed it. So while he who grasps the account alone may have some knowledge, this knowledge falls short of craft because it does not bestow on him a reliable disposition to produce health. Compare the phrasing in $E N$ 6.7: the knower knows the universal but not the particular. Such a knower would be like the incontinent who, while knowing that he should not drink, fails to recognise this particular instance as falling under that general truth. Such a person is exactly not practically wise. Similarly, a knower who just knew in general that light meat is healthy, because digestible, but was not able to recognise it in particulars would be no craftsman.

But this raises the further question: is experience on its own equally capable of ensuring success? Is this Aristotle's point when he says that 'for the purposes of acting, experience does not differ from craft'? Or is his thought that, while experience can sometimes ensure successful outcomes, and can do more than mere knowledge of the universal, experience is still not as reliable as experience with a logos exactly because of what the account contributes? I shall call the view that the logos helps ensure practical success the 'integrated' reading. Alternatively, we may conclude that it is entirely the element of experience in techne that ensures practical success and that this has nothing to do with the logos. The logos might then be considered an added nonpractical or purely theoretical element. ${ }^{35}$ I shall call this the 'discrete' reading. ${ }^{36}$

One thing to note is that the text at 981a3, while it allows for the discrete reading, does not require it. Aristotle says that 'For the purposes of acting experience seems not to differ from craft but we see the experienced being rather more successful than those (981a15) who possess an account without experience' (my emphases). The comparison is commonly taken to be between a craftsman who has the logos and an experienced person who has not. ${ }^{37}$ However, this reading is not mandatory. First of all, Aristotle does not refer to 'craftsmen' (technitas) here: ${ }^{38}$ rather he compares those who possess the logos, no more, with the experienced. Secondly, Aristotle is not stating himself that experience is as good as craft for practical purposes, rather he reports what seems to be the case (dokei, 981a13) and what we see. ${ }^{39}$ He then explains (aition de) this appearance in terms of how experience, like coming into being, is of particulars. But this may be taken also as an explanation of how things come to appear to us in this way rather than as an endorsement of the view itself. We do not have to conclude then, on the basis of this passage, ${ }^{40}$ that there are craftsmen that do not have experience, and so are ineffectual in bringing about the product. We may still maintain that the real craftsmen are those who have the logos with the experience. It has not been excluded that such craftsmen may be even more efficient that the merely experienced. What has 
been ruled out is that the mere possession of the logos is sufficient to ensure practical success without the element of experience. But we need not deny that proper craft requires both experience and logos.

\section{The practical significance of the logos}

What does the craftsman's logos say? Aristotle contrasts craft with experience both in terms of craft's grasping the universal cause and the logos. Similarly, Aristotle contrasts irrational powers like the power of the hot to heat things up with the master craftsmen who 'have the logos and grasp the cause' (981b6). So it seems reasonable to infer that the logos somehow states the universal cause. Having this kind of logos would also make good sense of the how the craftsman characteristically is able to teach: the craftsman teaches the student how to make the artefact through an account of the cause of the artefact.

There is no reason why Aristotle in Metaph. A.1 should dwell on the possible practical advantages of the craftsman's logos: his suggestion is after all that the universal cause represented in the logos anticipates theoretical knowledge. In contrast, the practical aspect of the logos comes to the fore in Metaph. $\Theta .2$. For here Aristotle's interest lies exactly in craft as a power (dunamis) to produce:

T4 Since some origins like this are present in what is soul-less, while others are in what has a soul, and are in the soul, and are in that part of the soul which is rational, it is clear that of capacities too some will be non-rational, while others will be rational. That is why all crafts are capacities and productive sciences are capacities. For they are origins of change in something else, or in the thing itself qua something else. As regards those capacities which are rational, the very same capacity is a capacity for opposites, but as regards the non-rational capacities a single capacity is for one thing: for example, heat only for heating, while the medical craft for both disease and health. The explanation of this is that knowledge is an account, and the same account shows both the thing and the privation, though not in the same way, and in one way it concerns both, while in another way it concerns rather the positive. So it is also necessary that such sciences should be of opposites, but concerning the one per se while concerning the other not per se. For indeed the account concerns one opposite per se, but concerns the other opposite in a way incidentally: for it is through denial and negation that it clarifies the opposite - for the primary privation is the opposite, and this is the negation of the other. ${ }^{41}$ 
Aristotle characterises craft as a power 'with an account'; it is meta logou as in EN 6.4. It is by having this account that the craft is able, characteristically, to bring about opposite outcomes. Medicine can kill or cure. Powers without an account can bring about one opposite only: for instance, fire can only heat things up and not also cool them down. And this, Aristotle says, is because the logos shows the doctor how to bring about health, while in so doing, it also suggests how to do the opposite. For example, if the account tells the doctor to treat a diabetic with this much insulin, for such and such a reason, she will also know that a larger or smaller amount will damage the patient in such and such ways.

Already Socrates in Republic 1 (333e-334b) had reflected on the ability of crafts to bring about opposite effects. So he argued that if justice is the craft of protecting people's property, then the just man ought to be equally adept at stealing. Aristotle's answer is to distinguish the way in which the logos shows the opposites. The logos does not show health and its opposite 'in the same way'. For health is what the logos is about per se, it is only of disease by accident. While medicine may enable you to kill, in killing you are not realising what medicine is really about. T4 confirms what already the $E N$ gave reason to believe, that the logos is not a mere accompaniment of the productive ability or state, but is something that gives you this ability. Indeed, Aristotle in T4 goes so far as to say that the knowledge, that is the craft, is the logos.

Is it possible to maintain the discrete reading in light of T4? Could one still insist that it is the element of experience alone which gives the craftsman the practical ability? I have claimed that the logos must be relevant to craftsman's practical success. For it is the logos that shows the doctor how to produce either of two outcomes. Without the logos the doctor would only be able to produce at most one outcome. ${ }^{42}$ But then his dunamis would not count as rational, let alone as technē. What T4 highlights is that the craftsman knows how to produce certain opposite outcomes because the logos shows him one opposite and thereby necessarily also its opposite. ${ }^{43}$

Perhaps one could charge this claim with the fallacy of division. From the fact that the logos enables the craftsman to produce (non-simultaneously) both outcomes, it does not follow that the logos is responsible for his ability to produce each of them. Consider a doctor who is able consistently either to kill or to cure. Could one not hold that it is his experience that gives him both the abilities to cure and kill, while it is the logos that enables him to activate one rather than the other? The logos would then throw the switch, as it were, between the ability to cure and the ability to kill that experience independently had given him. In this case, however, there would not be one ability, one dunamis, at work. Rather there would be two abilities, one to kill and another to cure. 
So unless the objector wants to use the example as a model for reducing two-way capacities to two capacities, the example seems beside the point. Moreover, it is hard to see what it would be about a general logos of health that would explain which of the two options on a given occasion is activated. This, after all, is the role ascribed in Metaph. $\Theta .5$ (1048a11) to desire or choice, not the logos. Rather, the logos is what gives the craftsman the ability to act both ways, not what decides which way he acts. Techne is then a two-way capacity not in the sense that it is two capacities rolled into one, but that it is one capacity that because of the logos allows for two possible outcomes. This means that when one is bringing about either of the opposites one does so in a manner that depends on the presence of the logos, insofar as it tells you either per se how to bring about health or per accidens how to do harm. T4 seems, then, to demand that we take the logos as grounding the craft's ability to bring about certain results.

Another version of the fallacy of division objection, suggested to me by Jessica Moss, would have it that, while experience is sufficient for the doctor to be able to cure, she needs the logos also to be able to harm. In this case, the logos would be presupposed by the doctor's having both abilities, but not responsible for her having each ability. However, this objection seems to be met by Aristotle's claim that the doctor's ability to cure follows from the doctor's logos of how to cure. The doctor's logos is per se of health. It is only because the doctor's logos tells her how to cure that it will also tell her, per accidens, how to kill. So it doesn't seem right to make the function of the doctor's logos primarily that of explaining how she can do harm.

We have seen how the logos offsets craft from mere experience. But it also distinguishes craft from another set of producers, whom T2 referred to as 'manual workers'. There is a striking parallel between the description of the logos-less or irrational powers in T4 and that of the manual workers in T2. In T2 Aristotle said:

That is why in each case we think the architects are more honourable and more knowledgeable than the manual workers, and wiser, because they know the causes of the things that are being made $<$ but the others - just as certain soulless beings make things not knowing what they make, as for example fire burns, so, while the soulless make each of these things because of their particular nature, the manual workers do so by habit>; [the architects] we think are wiser not because they are practical but because they themselves possess the account and know the causes. Generally, being able to teach is a sign of the person who knows and of the person who does not know and because of this we think that craft more than 
experience is knowledge. For [the craftsmen] are capable, while the others are not capable of teaching.

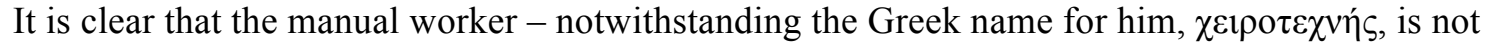
properly in possession of the techne. The sign of possessing the technē is the ability to teach and for want of the logos the manual workers cannot teach. In Metaph. $\Theta .5$ (1047b33) Aristotle contrasts powers acquired by habit from powers such as techne that are acquired by learning. ${ }^{44}$ When we are told in $\mathrm{T} 2$ that the manual workers work by habit this marks a contrast with the logos-based activities of the craftsmen. The manual workers are even compared to soulless things, which work the way fire burns, not knowing what they are doing. From the point of view of T4 - here the conspicuously similar example is heat heating - the comparison places the manual workers on the side of an irrational power, and not a rational power like craft. The polar opposite in $\mathrm{T} 2$ of the manual worker, and the star example of the craftsman, is the architectonic or master craftsman, he who fully grasps the account and the cause. We can of course imagine lesser craftsmen who grasp the cause to lesser degrees, but in this they would still distinguish themselves from the manual labourer.

Perhaps surprisingly, then, at the end of Metaph. A.1 Aristotle places the manual worker higher than the experienced person:

T5 The experienced person seems wiser than those who have whatever sort of perception, while the craftsman seems wiser that those who experienced, the architect than the manual worker, and the theoretical sciences more than the productive ones. ${ }^{45}$

Why should the manual worker be thought closer to wisdom than the experienced person if neither knows the logos or the reason why but only the fact that? The simplest answer is that the manual craftsman, while he does not possess the craft himself, takes orders from the master craftsman and so is informed by the logos. The manual worker works according to (kata) the logos though not with (meta) the logos, to use the distinction of EN 6.13. The experienced person is not guided by the logos, but follows only his own experience based on limited cases. The manual worker in contrast will have learnt by habit to work in the manner of a craftsman. All his movements will, like that of a tool properly wielded, be informed by the art, though it will not be in virtue of his own active reasoning or grasp of the $\log o s .{ }^{46}$ One might think of the difference between a medical assistant performing basic medical procedures under the guidance of a doctor and the experienced layman we 
encountered in T2, who may effect certain cures but with no direction by the craft. The medical assistant may be said to be closer to wisdom than is the experienced person in that he at least follows and executes the logos of the craft and while he does so passively not understanding what the logos says, he also follows it non-accidentally insofar as he follows the doctor's orders.

\section{The theoretical status of the logos}

As mentioned, scholars sometimes refer to the logos of the craft, as it features in Metaph. A.1 as 'theoretical'. ${ }^{47}$ The reason is evidently that the logos states the universal cause in a way that foreshadows theoretical knowledge. Moreover, Aristotle in T2 contrasts master craftsmen as being wiser because they have the logos and not because they are practical. So one might infer that the $\log o s$ is a theoretical component of the craft.

In T4 Aristotle said that the logos 'shows' the subject matter (dēloi to pragma). In principle such showing might mean no more than 'indicating' the subject matter, but if so it would be hard to see the contrast with the experienced person: even the merely experienced can say something to indicate health and its opposite, as we saw. Given that Aristotle thinks that the logos makes the craft episteme $\bar{e}$, it seems likely that 'indicating' means showing what the thing is, i.e. that it will be an account of what the thing is. ${ }^{48}$

However, we should not assume for this reason that the logos is what Aristotle would take to be a scientific definition. This would be a definition, say of health, that states the essence of health and serves as premise in syllogisms demonstrating other features of health, in the manner envisaged by APo. T4 might bolster this impression when he calls the logos epistemen and says that it is of health per se. However, as we saw in the discussion of the EN (T1), not only are there weaker and stronger notions of episteme, but we should also note that the claim that the logos of medicine is of health per se should be parsed as 'the craft's logos is-per-se of health' and not as 'the logos of the craft is of health-per-se'. This means that the logos is of health insofar as it is the logos it is, that is the logos of medicine. So while it is clear that the logos of health will state a cause of health, it is not implied that the logos will state the cause in the manner of the essence of health. That may belong to another epistèmé.

What sort of causal information does the account then provide, and does it in any way count as theoretical? Returning to Metaph. A.1, Aristotle here talks of the craftsman grasping the universal. For example, he is able to single out the one eidos in virtue of which the medicine helped Socrates, Callias and so on different occasions, given that they were phlegmatic or bilious: 'But it is proper to craft to judge that this helped all such people differentiated as a single kind suffering from 
this here disease, for example to the phlegmatic or bilious when they are burning with fever' (981a10-12). This suggests that the doctor has a knowledge of kinds of disease and knows which kinds of medicine will work against which kind of disease. Note also, however, that the universal, the disease, is identified with reference to the cure. There is no implication that the doctor knows the universal disease in any way other than as it is relevant to the cure. There may then be a more fundamental account of what it is to be phlegmatic or bilious and there may be a more fundamental way of understanding the properties of the medicine. There may even be a more fundamental way of understanding the causal relationship between the two. What the doctor understands is why it is that this medicine alleviates this disease in the context of healing.

The notion of higher and lower causes is well known from the theoretical sciences. So Aristotle tells us in APo 1.13 that some theoretical sciences explain others that are closer to the perceptible facts (78b34-79a6, tr. Reeve):

T6 The explanation differs from the fact in another fashion, when each is considered by means of a different science. These are sciences that are related to one another in such a way that the one is under the other, as, for example, optics is under geometry, mechanics under solid geometry, harmonics under arithmetic, and star-gazing under astronomy . . . For here it is for the scientists who deal with perceptibles to know the facts and for the mathematical scientists to know the explanations. For the latter possess demonstrations that give the explanations, and often they do not know the facts, just as people who have theoretical knowledge of universals often do not know some of the particulars through lack of observation.

It is clear from other passages that Aristotle thinks that a similar sort of explanatory relationship can obtain between a theoretical science and a craft, where the one does not fall under the other within a demonstrative system. So medicine uses geometry to explain how wounds heal differently ( $A P o$ 1.13 79a10-15, tr. Barnes):

T7 Related to optics as this is related to geometry, there is another science related to it - viz. the study of the rainbow; for it is for the natural scientist to know that fact, and for the student of optics - either simpliciter or mathematical - to know the reason why. And many even of those sciences which are not under one another are related like this - e.g. medicine to geometry; for it is for the doctor to know the fact that circular wounds heal more slowly, and for the geometer to know the reason why. 
Medicine also relies on natural science to demonstrate the basic truths about health and disease (De Sensu 1, 436a17-b1, revised Oxford tr. by Beare, modified):

T8 It belongs to the natural scientist to obtain also a clear view of the first principles of health and disease, inasmuch as neither health nor disease can occur in those deprived of life. Indeed, we may say of most physical inquirers, and of those physicians who study their craft more philosophically, that while the former complete their works with a disquisition on medicine, the latter start from a consideration of nature.

There is an overlap, then, in what the natural philosopher and the doctor study: there are first principles of health and disease which belong both to natural science, because health and disease are functions of living beings qua living, but also of course to medicine, because the doctor needs to know about them as causes of health and disease. There is a clear theoretical component to the doctor's causal knowledge, although the causes he needs to understand are not basic to the study of nature or to the study of living beings as such. What this adds to the picture is that it is not just in the theoretical sciences that one science adopts the conclusions of another as its principles. Sometimes the same holds true of the productive sciences in relation to the theoretical: sometimes medicine takes its principles from natural science just as optics borrows its principles from geometry.

It should be clear also from the medical example that craft cannot be understood as distinct from theoretical science in the sense that its logos contains information that is only about the particular and contingent. Medicine will grasp necessary, universal propositions about the causes of health and disease which occur also as conclusions of theoretical science.

Is the more theoretically inclined doctor then simply a low-grade natural philosopher? ${ }^{49}$ No: clearly the end of medicine as a productive techne remains the production of health in patients. The defining end of medicine is a state of affairs, health, which depends on the activity of the doctor. Medicine deals with the contingent which is under our influence. It aims at bringing about health in particular patients, which is indeed the only level at which health can be brought about. Theoretical knowledge as such does not change anything: it deals with eternal and necessary truths. However, the point that productive and theoretical knowledge have different ends does not mean that productive knowledge cannot rely on or use theoretical knowledge. So Aristotle points out in Eudemian Ethics $(E E)$ that theoretical sciences may be practically useful but also that this is 
accidental to them as theoretical $(1.5,1216 \mathrm{~b} 2-16$; revised Oxford tr. by Solomon, slightly modified):

T9 This is correct with regard to theoretical knowledge, for there is no other part of astronomy or physics or geometry except knowing and contemplating the nature of the things which are the subjects of those sciences; though nothing prevents them from being in an accidental way useful to us for much that we cannot do without.

We saw a good example of this in the doctor's use of geometry in understanding why circular wounds heal more slowly. The doctor learns about general scientific truths which she can employ in her therapy. Such truths may be accidentally useful from the point of view of theoretical science but that does not mean that their status as universal truths is accidental to their usefulness to the doctor. On the contrary, a doctor will seek accounts of the necessary and universal features of diseases and their treatments because it is such accounts that will ensure the applicability and reliability of her therapy to a multitude of cases. It may even be a doctor, rather than a natural philosopher, who undertakes the research into the aetiology of a disease because she wants to find a cure. What limits the scope of the doctor's logos, as such, is not the distinction between the necessary and the contingent, but the extent to which necessary causes are relevant to the end of bringing about (the contingent) health of patients. ${ }^{50}$

We would expect the logos of the craft to feature theoretical information but only to the extent that it is instructive in production. A good way to think of the logos here is as a recipe. If you are to make ice-cream expertly, or teach another person the skill, you need to know about processes of emulsion, stabilising and freezing. The artisan ice-cream maker may well know that emulsifiers include lechitin, but there is surely no need for her understand its chemical structure (phosphatidylcholine) or how this works in gelling the ice-cream; and similarly she will understand the importance of stabilisers for making the ice-cream creamy, and know that egg whites or other proteins do the job, but again she need not occupy herself with the molecular structure of such proteins. An Aristotelian craftsman may know that protein is a stabiliser and in this he differs from the experienced who will just know that egg white has worked to smooth the mixture in the past. But the craftsman need not know the chemistry at work. And that is because she is just interested in making a particular product, ice-cream.

The difference between craft and natural philosophy here is not necessarily that craft always avails itself of information at a lower level of generality than the principles of any 
theoretical science. We might imagine a mathematician studying the principles of particular round shapes, say ellipses, while the doctor is interested in all round shapes in the context of healing. What matters more than the level of generality here is the selectiveness of the interest in the causal mechanisms relevant to just to this product.

The information contained in the logos, that this $x$ produces $y$, can then be in the form of a general causal statement. The same information can also occur in the context of a theoretical science, typically as a conclusion, as a statement of a fact that a theoretical scientist given his distinct causal interests will seek to explain at a more fundamental level than concerns the craftsman. This feature of craft's use of theoretical information is not a feature of it qua applied, as we saw, since many theoretical sciences take as their starting points principles that are established by higher theoretical sciences. What characterises the craft's use of theoretical information is its end: the product that is to be brought about determines the selection of the theoretical information invoked. The logos of the craft should not be seen as either theoretical or practical if these are considered mutually exclusive, since the information presented is adopted from theoretical science insofar as it serves a productive purpose.

One way one may express this kind of point is to distinguish between the subject matter or domain of craft and its purpose. ${ }^{51}$ The domain of craft may overlap with that of theoretical science insofar as craft draws on information that is necessary and universal. But the purpose of craft is distinct: to produce something contingent and particular. When Aristotle says in EN 6.4 (T2) that craft is concerned with the contingent, he means to define craft in terms of its end or final cause, as we would say that medicine is the craft whose purpose it is to produce health in particular patients. ${ }^{52}$ However, in producing this end the craft will avail itself of universal, necessary truths, as appropriate to this end. ${ }^{53}$ As productive knowledge it is the end which defines the craft as such. An analogy from another productive ability, nutrition: the nutritive capacity is defined in terms of its end, preserving the living body as such; but in performing this function the nutritive soul uses food of a different sort from the body itself ( $D A 2.4$ ). Similarly, craft is defined in terms of a particular product, but uses suitable universal and other information to that end. While the craft draws on universal truths in a way that distinguishes it as knowledge, overlapping as we seen with the domain of theoretical science, it is the relationship to a particular outcome that marks it off as productive knowledge. As Aristotle said in Metaph. A.1 (T2), the doctor is only concerned accidentally with the universal 'man'. The defining aim of his craft, the final cause, is curing particular men; if the doctor draws on universal information about 'man' it is not because it is universal that he is interested in this information but because it contributes to his therapy. 
A final objection: one might grant the integrated reading's general claim that for Aristotle the logos helps ground the craftsman's productive ability, but still argue that for the purposes of Aristotle's specific argument in T2 we should consider the logos as a detachable theoretical element: for is it not after all the theoretical, non-practical character of the logos that makes techne a

step on the way towards wisdom $?^{54}$ In reply, it should be said that even on the integrated reading the logos anticipates theoretical knowledge. While the logos represents an account geared towards the production of a particular outcome, it is, as we have seen, universal and causal in a way that may overlap with conclusions articulated in theoretical science. The logos in this way still serves to contrast techne with experience. One might add that the rhetoric of the passage also requires that the craftsman should not be taken to be a theoretical thinker-cum-producer, as understood on the discrete reading. By insisting on the productive orientation of the craftsman's logos, it is clear that no craftsman, not even the master craftsman, talks of universal causes in quite the same manner as the theoretical scientist. The integrated reading of T2 might then suit the argument's crescendo towards wisdom even better than the discrete reading: the craftsman is not so much a hybrid creature, as on the discrete reading, but a third distinct character recognizably similar to, but not to be confused with, either the merely experienced or the theoretical scientist.

\section{Craft, nature and necessity}

The logos of craft deals with general causal mechanisms of the sort also theoretical sciences may deal with, though in a different manner. The same processes that craft employs are often those that we observe in nature. In the Physics, Aristotle stresses the parallel between craft and nature (2.8, 199a12-19 (tr. Hardie and Gaye):

T10 Thus if a house, e.g., had been a thing made by nature it would have been made in same way as it is now by craft; and if things made by nature were made not only be nature but also by art, they would come to be in the same way as by nature. The one then is for the sake of the other; and generally a craft in some cases completes what nature cannot bring to a finish, and in others imitates nature. If, therefore, artificial products are for the sake of an end, so clearly also are natural products. The relation of the later to the earlier items is the same in both.

What Aristotle means by the relation of the later to the earlier is in both cases that of final causation: the earlier is for the sake of the later. But the earlier is also necessary for the sake of the later, by that notion of necessity that is distinctive of final causation: hypothetical necessity. Natural 
processes, natural bodies and their parts are necessary for certain ends. The ends explain those natural features as their final cause. While Aristotle distinguishes causation of craft from that of nature in several ways, hypothetical necessity is not one of them. On the contrary, Aristotle uses craft exactly to highlight the role of hypothetical necessity in nature. ${ }^{55}$

So when we read in EN 6.4 that craft deals with the contingent and theoretical science with the necessary, we should be careful to distinguish hypothetical necessity from the necessity that serves to contrast the two. The fact that there are always and necessarily human beings makes them objects of theoretical wisdom, and ensures that the hypothetically necessary processes required to bring about humans will always be realised. But hypothetical necessity may equally be at work when the end is not always necessarily there. The hypothetical necessity is after all just that: hypothetical on whether or not the end is to come about. The difference is then that the hypothetical antecedent is always (or for the most part) realised in the case of natural beings, like humans, while it is only realised in craft contingently on the presence and disposition of a craftsman. But once the craftsman works he can avail himself of the same processes that we observe in nature, processes that necessitate their ends. Consider the case of healing through heating. Heating is hypothetically necessary if the patient is going to recover. Sometimes this happens spontaneously - perhaps a

particularly warm spell of weather brings it about -, sometimes a doctor does the heating. ${ }^{56} \mathrm{We}$ say in the former case that health is brought about by luck because this is the sort of thing somebody, a doctor, would do in order to bring about health, but in this case it happened to come about through nature. So the process, heating, and the effect, health, are the same in the two cases. And that is also why the doctor can learn from nature: there are processes in nature that necessarily bring about health which a doctor can make use of to bring about his desired ends. The logos will give information about such processes.

\section{The usefulness of the logos}

We have seen that craft is a productive power grounded in the information provided by the logos about how to produce of a particular kind of artefact. The integrated view rather than the discrete reading has emerged as correct. We might in principle allow for the person of experience to be as effective on individual occasions as the craftsman who possesses the logos. But is there any reason to think that a craftsman because of his logos will generally be more effective than the man of mere experience?

In $E N$ 10.9, Aristotle expresses a preference for individualised education and draws the parallel with medical treatment: a patient is more likely to get the treatment he needs when the 
doctor attends to the particularities of his case. But he then adds the following (1180b13-23, tr. Irwin, slightly modified):

T11 Nonetheless a doctor, a gymnastics trainer, and everyone else will give the best individual attention if they also know universally what is good for all, or for these sorts. ${ }^{57}$ For sciences are said to be, and are, of what is common [to many particular cases]. Admittedly someone without knowledge (anepistèmona) may well attend properly to a single person, if his experience has allowed him to take exact note of what happens in each case, just as some people seem to be their own best doctors, though unable to help anyone else at all.

Nonetheless, presumably, it seems that someone who wants to be an expert in a craft and a branch of study should progress to the universal, and come to know that, as far possible; for that, as we have said, is what the sciences are about.

The case of the experienced person who is able to attend to one patient but not others suggests that the limitation in the range of this person's abilities comes from the limitation in the scope of the information he possesses: grasping the universal tells you what is good for the patients universally or 'for these sorts', as Aristotle specifies. That is, the universal will tell you how to treat a certain sort of patient, a phlegmatic or bilious one, to use the examples of Metaph. A.1. We might say, then, that the basic problem with mere experience lies with the limited scope of application. Knowing the universal allows you to attend to all the relevant cases.

T2 can be read as developing this kind of point. Aristotle said there that 'it is proper to craft to judge that this helped all such people differentiated as a single kind suffering from this here disease, for example to the phlegmatic or bilious when they are burning with fever'. Identifying the patient as phlegmatic rather than bilious allows the doctor to prescribe a treatment that is appropriate to him. The feverish symptoms may be the same and not distinguishable to the simply experienced person. But the doctor will understand how different treatments are appropriate to them. Typically in the sort of Hippocratic context Aristotle has in mind, a bilious person will be prescribed a treatment that counterbalances his bilious condition and so this treatment will differ from that prescribed to the phlegmatic. ${ }^{58}$ The merely experienced person cannot simply on the basis of the patient's symptoms prescribe the right medicine. Knowledge of the relevant universal, as provided by the logos, is required to make the right recommendations.

Or consider a non-medical example. Imagine an experienced ship-builder who knows that wood floats, having successfully built many ships out of wood. Contrast with him a nautical 
engineer who knows why wood floats, namely that wood's density is less than that of water. This engineer therefore also knows that ships may be built out of materials other than wood, as long as they also have this property. The engineer may succeed in making ships out of a range of materials that the merely experienced ship-builder would stay clear of. She will also know, however, that not all wood floats, again because she understands what makes materials buoyant. And so she may not attempt to build a ship out of, say, leadwood (combretum imberbe), which the merely experienced shipwright might mistakenly choose. Causal knowledge allows the craftsman to extend her productive knowledge successfully to a range of different scenarios. ${ }^{59}$

In $E N 5.9$ Aristotle describes how difficult it is to know how to act justly (1137a12-17, tr. Irwin):

T12 Knowing how actions must be done, and how distributions must be made, if they are to be just, takes more work than it takes to know about healthy things. And even in the case of healthy things, knowing about honey, wine, hellebore, burning, and cutting is easy, but know how these must be distributed to produce health, and to whom and when, takes all the work it takes to be a doctor.

Other people, and here we must include the merely experienced person, may know about various health remedies ${ }^{60}$ but such knowledge does not a doctor make. The doctor's knowledge is much more fine-grained. Because the merely experienced person does not understand the disease whose symptoms he observes, nor can he recognise what strain of the disease it is, at what stage of the disease it is, or how severe a case it is, or, therefore, how much of the appropriate medicine this patient must take and when and how often. It is the doctor's causal knowledge of the disease that allows her to modulate the treatment as appropriate to the particular patient.

This logos-based ability to adapt one's expertise to particular circumstances should not be confused with the point that the doctor needs experience to recognise the symptoms of the individual case. It may take careful observation and comparison of symptoms to diagnose the patient as, say, phlegmatic. A merely experienced person who has seen various such cases may do better at spotting a disease ('Chickenpox!') than the inexperienced trainee doctor. The point here is rather that given this experience the doctor will in virtue of her causal knowledge be better able to recognise the disease in the way that allows for individualised therapy. ${ }^{61}$

The ethical parallel is with the prudent man who sees the particular situation as falling under the relevant universal. As we have come to expect, Aristotle mentions a case from medicine 
to illustrate his point. What is right for one person is wrong for another: ten pounds of meat is too much for me but appropriate for Milo, the champion wrestler (EN 2.6, 1106a35-b6). Having this knowledge will give the craftsman a sensitivity to the particular causal features of a situation that makes this the right way to proceed. This, again, is not done without experience, but it is a logosbased ability to modulate one's productive ability according to the circumstances. To sum up, the logos gives the craftsman the ability to extend and adapt his work to the full range of relevant cases. $^{62}$

As a coda, we may note an analogy with the role of logos in ensuring successful theoretical reasoning. Compare a geometrical case: you may know of this isosceles triangle and this rectilinear triangle that their internal angles equal 180 degrees because you have measured them. You may, as T11 put it, have taken 'exact note of what happens in each case'. You may even recognise them both as triangles. But you do not properly speaking know that they have angles equal to 180 degrees because you do not know that this holds true of them qua triangle. ${ }^{63}$ This is neither a matter of just accessing particulars, nor a matter of not grasping a universal at the right level of generality, but a matter of understanding what it is about the universal that makes the particulars have the property to be explained. And in the absence of such an account you will not be able to extend your knowledge that these individual triangles to other figures, say scalene triangles. ${ }^{64}$ The analogy with the logos of productive knowledge is that the ability to extend one's knowledge to relevant cases arises from the logos because the logos makes one sensitive to which features of the object causes it to be in this way. The geometer's account of the logos of the triangle allows her to identify and explain the internal angles of all triangles, while the doctor's logos of being phlegmatic or bilious will allow her to identify and treat all cases of this disease. In theoretical knowledge we can explain the full range of relevant objects if we have the right logos, in craft we can also produce them.

\section{References}

Angier, T. (2010), Technē in Aristotle's Ethics. London.

Annas, J. (2011), 'Practical Expertise' in J. Bengson and M. A. Moffett (eds.), Knowing How. Essays on Knowledge, Mind, and Action (Oxford), 101-12.

Bolton, R. (1991), 'Aristotle's Method in Natural Science' in L. Judson (ed.), Aristotle's Physics (Oxford), 1-29.

Bronstein, D. (2012), 'The Origin and Aim of Posterior Analytics II.19', Phronesis 57: 29-62. Bronstein, D. (2016), Aristotle on Knowledge and Learning. The Posterior Analytics. Oxford. 
Butler, T. (2003), 'Empeiria in Aristotle', Southern Journal of Philosophy 41: 329-50.

Cambiano, G. (2012), 'The Desire to Know (Metaphysics A 1)' in Steel 2012,1-43.

Charles, D. (2002), Aristotle on Meaning and Essence, Oxford.

Cooper, J. (1975), Reason and the Human Good in Aristotle, Cambridge, Mass.

Devereux, D. (1986) 'Particular and Universal in Aristotle's Conception of Practical Knowledge', The Review of Metaphysics 39: 483-504.

Frede, M. (2004), 'Aristotle on the Origins of Philosophy', Rhizai 1: 10-44.

Gregorić, P. and Grgić, F. (2006), ‘Aristotle’s Notion of Experience', Archiv für Geschichte der

Philosophie 88: 1-30.

Hasper, P. S. and Yurdin, J. (2014), 'Between Perception and Scientific Knowledge: Aristotle's Account of Experience', Oxford Studies in Ancient Philosophy 47: 119-50.

Irwin, T. (1999), Aristotle. Nicomachean Ethics. 2nd edn. Indianapolis.

LaBarge, S. (2006), 'Aristotle on Empeiria', Ancient Philosophy 26: 23-44.

Lonie, I. L. (1981), The Hippocratic Treatises, "On Generation," "On the Nature of the Child," "Diseases IV”: A Commentary. Berlin.

Makin, S. (2006), Aristotle. Metaphysics Book $\Theta$. Oxford.

Moss, J. (2014), 'Right Reason in Plato and Aristotle: On the Meaning of logos', Phronesis 59: 181-230.

Primavesi, O. (2012), ‘Aristotle, Metaphysics A: A New Critical Edition With Introduction' in Steel 2012, 385-516.

Reeve, C. D. C. (2013), Aristotle on Practical Wisdom. Nicomachean Ethics VI. Cambridge, Mass. Schiefsky, M. (2005), Hippocrates on Ancient Medicine. Leiden / Boston.

Steel, C. (2012) (ed.), Aristotle’s Metaphysics Alpha. Symposium Aristotelicum. Oxford.

\footnotetext{
${ }^{1}$ I am most grateful to Jessica Moss and Øyvind Rabbås for written comments on this paper, and to audiences at the Universities of Copenhagen, Oxford, Cambridge and Toronto for many helpful criticisms.

${ }^{2}$ There has been a healthy number of articles in recent years on Aristotle's account of experience, including Butler 2003, Gregorić and Grgić 2006, LaBarge 2006, Bronstein 2012 and Hasper and Yurdin 2014, which have illuminated how experience falls short of techne. However, the literature offers little detailed analysis of what positively goes into the logos of craft. Moss 2014 provides a most helpful general account of logos in practical and theoretical knowledge, but her brief is not to address the specifics of techne.
} 
${ }^{3}$ I shall have relatively little to say here about the parallel passage in Posterior Analytics 2.19 since, apart from its many interpretative difficulties, it does not mention the logos of craft and is much less explicit about how technē relates to either experience or theōria than is Metaph. A.1.

${ }^{4}$ I do not think Reeve 2013, 146 can be right to translate 'having theoretical knowledge of' since the object of theōrein as described here hardly allows for theoretical knowledge.

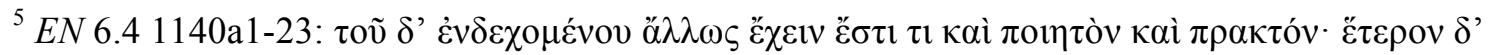

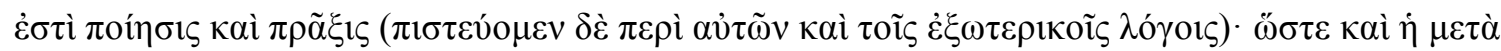

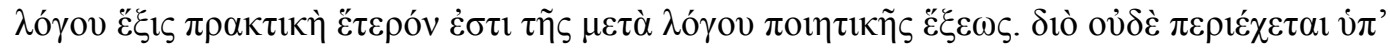

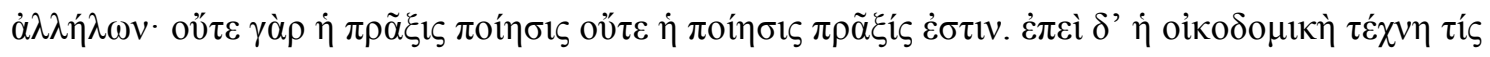

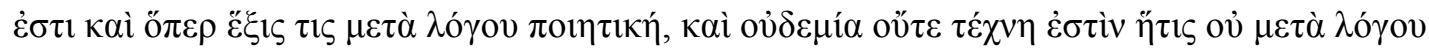

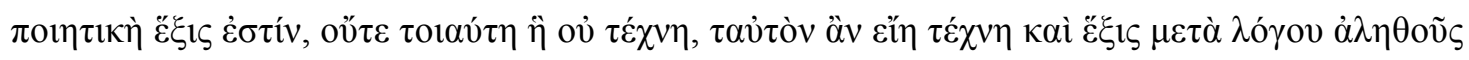

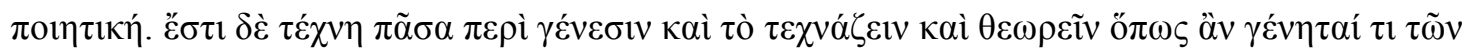

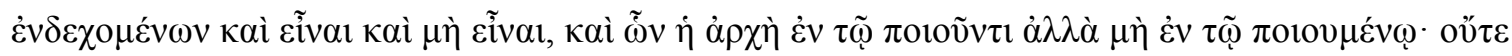

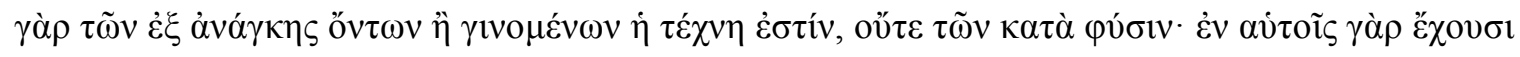

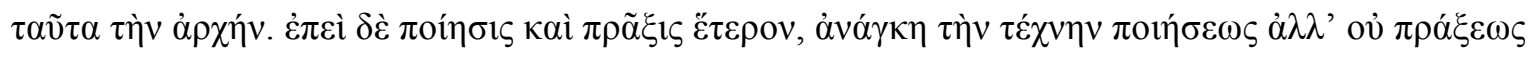

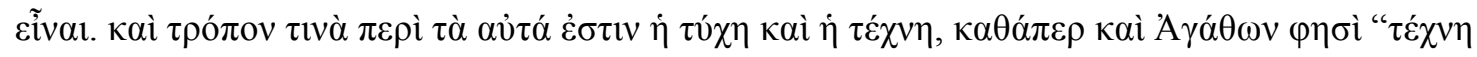

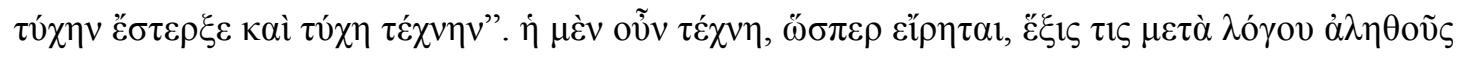

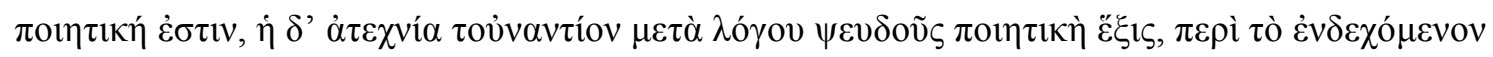
$\ddot{\alpha} \lambda \lambda \omega \varsigma \check{\varepsilon} \chi \varepsilon i v$.

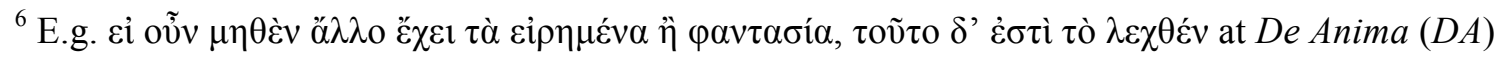
$3.3,428 \mathrm{~b} 30-429 \mathrm{a} 1$. 
${ }^{7}$ Logos has here received a variety of translations: 'reason' (Irwin, Reeve), 'course of reasoning' (Ross), 'prescription’ (Broadie/Rowe), even 'law' (Alexander Grant).

${ }^{8}$ While I am sympathetic to the argument of Moss 2014 that logos in 'right logos' should in the contexts of both practical and productive knowledge primarily be taken to mean 'account', I would stress the significance of her closing observation (at 228) that 'we can continue translating logon echon as "rational", and we can even insist that in certain passages logos is after all best translated as "Reason", so long as we bear in mind that we now know the focal meaning that underlies these derived ones'. One passage (not mentioned by Moss) where retaining this option is crucial is Metaph. $\Theta .2$ (T4), discussed below.

${ }^{9}$ The expression to logon echon might seem an unnecessarily roundabout way of speaking if logos itself meant rational capacity. However, we should not forget that Aristotle is identifying parts here by their capacity, so we should supply meros or morion in the expression.

${ }^{10}$ For example, in $E N 1.6$, discussed below.

${ }^{11}$ For the same reason I take it that we should not understand the expression 'a hexis with a logos' as a disposition to come up with the appropriate logos on each occasion. For the logos given on each occasion will be a function of the exercise of the disposition rather than the disposition as such. I am grateful to Jessica Moss for suggesting the possibility of this alternative reading.

${ }^{12}$ See Metaph. @.2., EE 1246a26-31, NE 1094a18; cf. Angier 2010, 38.

${ }^{13}$ It is not unusual for Aristotle that a generic term can also occur as a species term, where the species seems to be the outstanding instance of the genus: cf. his use of politeia in Politics 3-4.

${ }^{14}$ This use of $\mu \varepsilon \tau \alpha$ to indicate dependency is common in Aristotle, see e.g. $\mu \varepsilon \tau \grave{\alpha} \sigma \omega ́ \mu \alpha \tau o \zeta$ at $D A$ 403a15 and 16-17, and $\mu \varepsilon \tau ' \alpha i \sigma \theta \eta ́ \sigma \varepsilon \omega \varsigma$ at De Sensu 436b3.

${ }^{15}$ The passage, incidentally, also backs up the reading of logos as account in T1, since Socrates typically took the possession of a definition to constitute virtue, and no disagreement with Socrates is marked on this point. See Moss 2014, 190.

${ }^{16}$ Given the parallel with the logos role in getting the action right, it seems reasonable to infer that the logos similarly enables the craftsman to produce successfully, and not just, say, execute some of the other functions of logos such as to explain what he is doing or teach it. I thank Jessica Moss for pressing me on this point. 
${ }^{17}$ The reference is to Plato's Gorgias, where Polus uses the present tense, supporting the suggestion that epoiēsen is the gnomic aorist, made in correspondence by Sarah Broadie according to Cambiano 2012, 17 n. 32.

${ }^{18}$ Alternatively: 'all people', taking $\pi \tilde{\alpha} \sigma \mathrm{v}$ as masculine.

${ }^{19}$ Primavesi 2012, 452-4 suggests transposing these lines to after $981 \mathrm{~b} 6$.

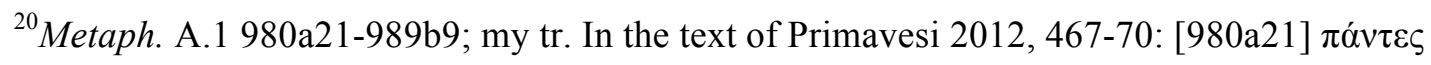

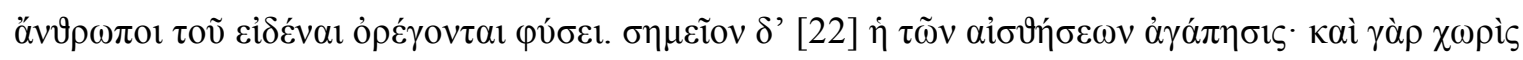

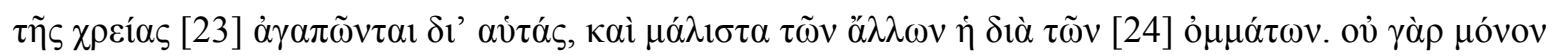

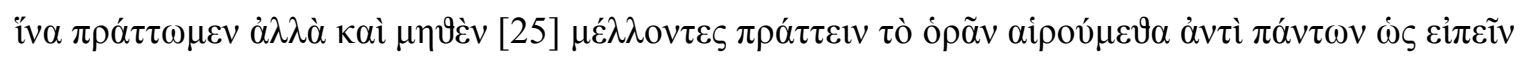

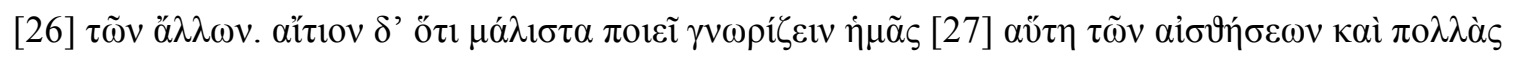

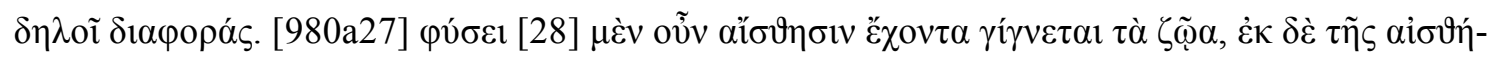

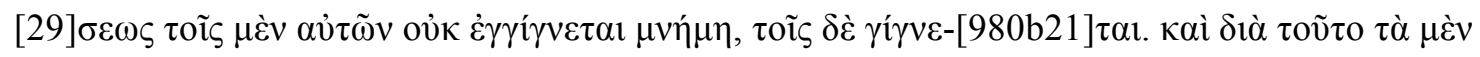

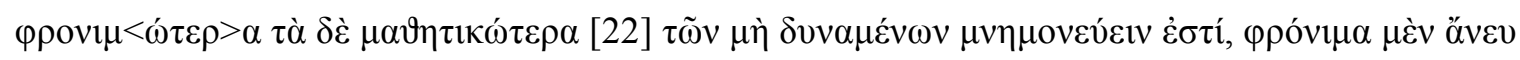

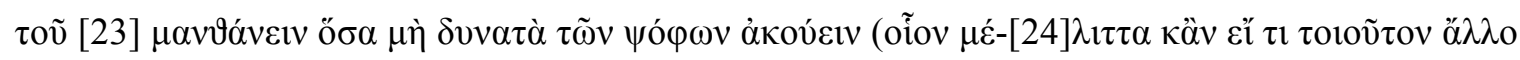

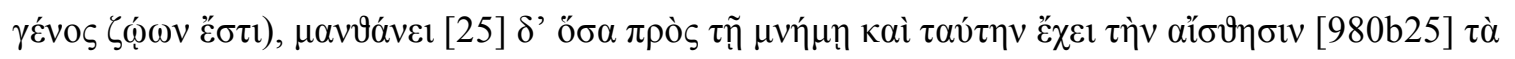

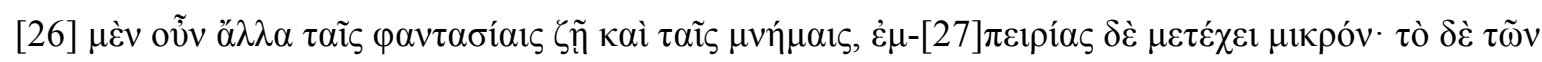

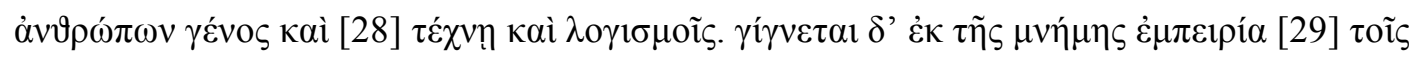

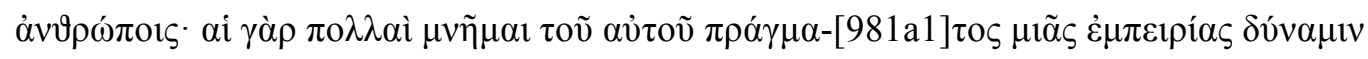

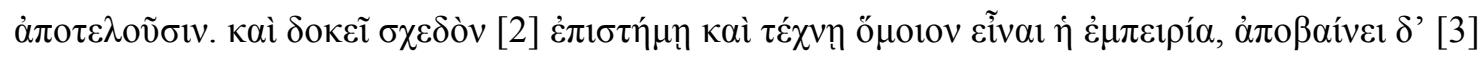

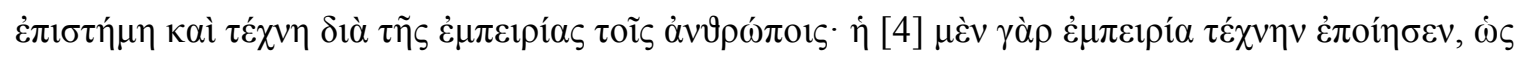

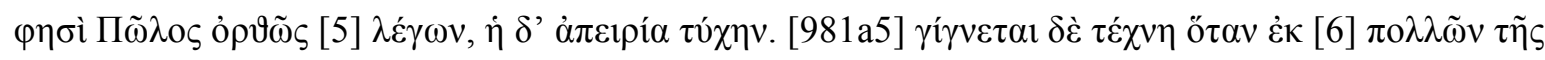

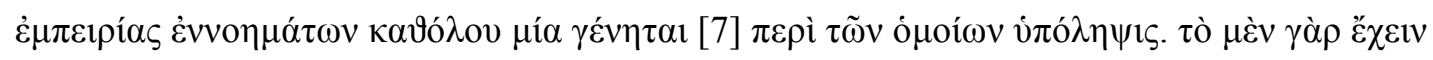
vं

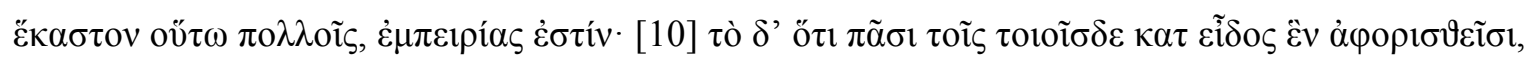

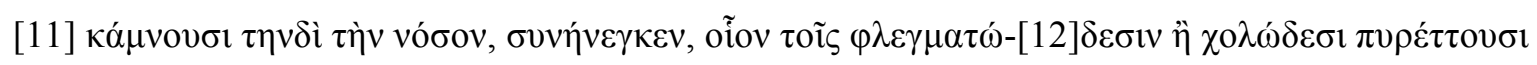

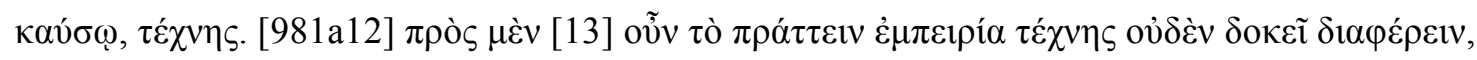

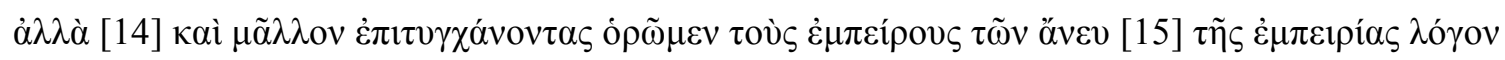

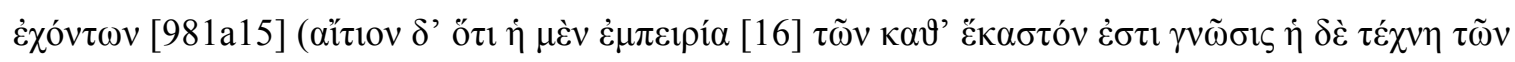

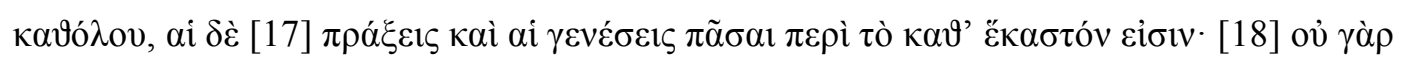

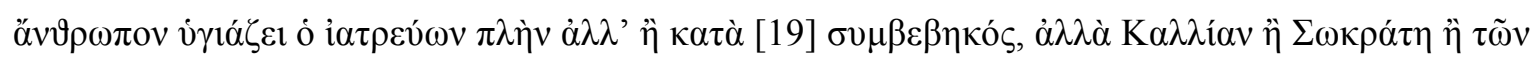

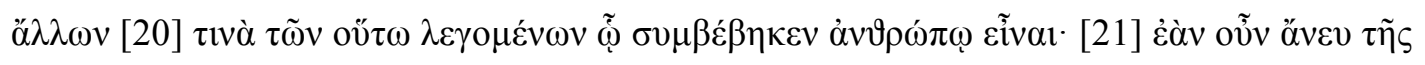




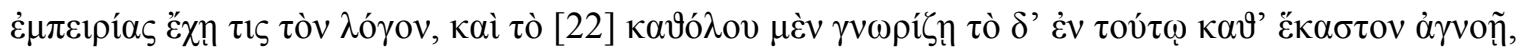

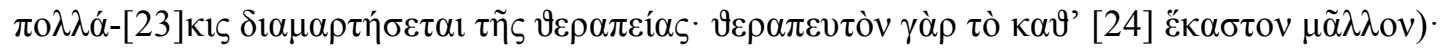

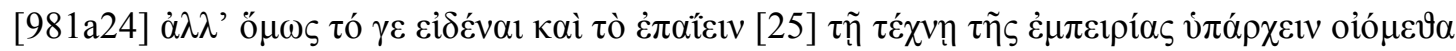

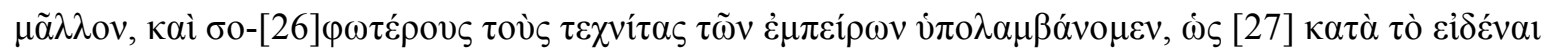

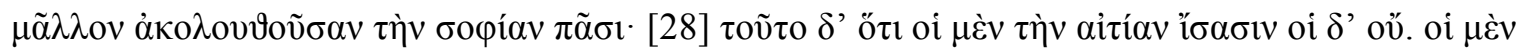

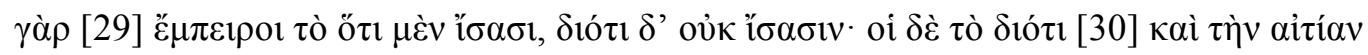

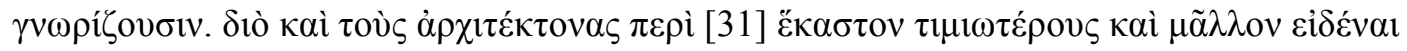

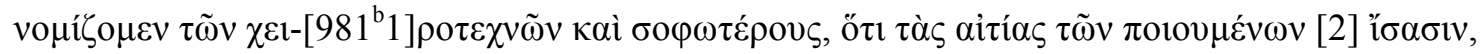
$\tau$ ov̀ $\delta^{\prime},-$

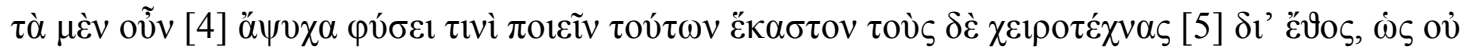

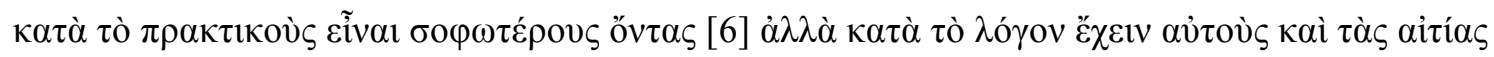

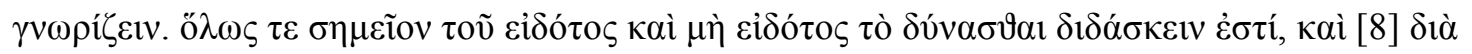

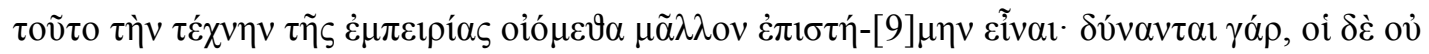

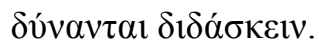

${ }^{21}$ The qualification $\tau$ oĩ $\grave{\alpha} v \theta \rho \omega ́ \pi 01 \varsigma$ (980b29, 981a3) offsets human from divine knowledge, which requires no experience.

${ }^{22}$ I take it that, while memory is a necessary condition of experience, and experience of craft, in the sense that each previous state provides information required for the following, craft is not in the same way a necessary condition of theoretical knowledge. (Of course, craft is a necessary condition of theoretical knowledge in a different way in that it helps provide for the necessities of life, allowing us thereby the leisure to pursue theoretical studies, as Aristotle points out in the lines following T2, 981b14-24.)

${ }^{23}$ On discrepancies between modern and ancient conceptions of craft, see also Annas 2011, 105.

${ }^{24}$ As Schiefsky 2005, 351 rightly observes.

${ }^{25}$ As argued by Hasper and Yurdian 2014, 123 n. 8.

${ }^{26}$ One might object that the experienced person just requires access to particular similarity relations which may obtain between individual pairs of experiences. But Aristotle tends to view similarity in terms of sameness of form, cf. Metaph. 1054b3-13, e.g. the larger square is like the smaller in terms of both being squares. Also it seems clear that he in T2 is predicating the same disease, and the same medicine, of the various cases. 
${ }^{27}$ Ross 1924, 117 cites Jackson for the point that: ' $\varphi \lambda \varepsilon \gamma \mu \alpha \tau \omega \dot{\delta} \eta \varsigma$ and $\chi 0 \lambda \omega \dot{\delta} \eta \varsigma$ describe not a disease but natural hexeis, cf. EN 1181b3, Problemata 1.9, 11, 12.' However, even if we take the terms to refer to states, they are still picked out here as relevant to a particular disease and its treatment, as shown also by $E N 1181 \mathrm{~b} 3-5$.

${ }^{28}$ See, e.g. APo 71b9-12 ; for discussion see Gregorić and Grgić 2006 and Bronstein 2016, 51-6.

${ }^{29}$ This kind of interpretation is generally supported by recent writers on the subject: Devereux 1986, 490; Butler 2003, 338-40; Gregorić and Grigić 2006, Bronstein 2012, Hasper and Yulin 2014. ${ }^{30}$ My account here owes much to that of Charles 2002, 152: 'In each case, the relevant person with experience has no more grasp on illness or medicine than is given by her ability to discriminate particular instances on the basis of their being like other particular cases. She will lack the conceptual sophistication required to understand the illness as (e.g.) fever of a general type, in terms which do not essentially involve reference to other particular cases. Thus, she will not grasp universals, if the latter are to be understood as wholly general and completely abstracted from particular cases. But precisely this understanding of universals seems to be what is suggested both by the examples given in Metaphysics A.1 and by the phrase "the universal . . . the one over and above the many" (as used in Post. An. 100a6 f.). For, the latter clearly expresses the idea of a universal as something to be understood without any essential reference to particular cases.' However, I think Charles goes too far when he argues against the view of Bolton that experienced people possess a confused universal that 'Aristotle's position is far more radical: people with experience lack universals altogether' $(152 \mathrm{n} .13)$. This goes too far, in my view, because the experienced does have a grasp of chickenpox but one that simply generalizes from the symptoms observed in the particular cases.

${ }^{31}$ Trendelenburg athetizes these words.

${ }^{32}$ Or on Trendelenburg's reading, 'that it is light'. One might think that the causally pertinent universal is also more universal than the universal that the merely experienced entertains (I owe this suggestion to Jessica Moss). So, for example, 'digestible' may be more universal than 'chicken' as there are other kinds of digestible foods. But it is not clear that this will always be so. For example, in the case of fevers, it seems that the cause 'biliousness' represents just one kind of fever. 
${ }^{33}$ Irwin 1999, 245 notes: "In this passage, "particulars" seems to refer to relatively determinate types (e.g. "bird meat" as opposed to "light meat") rather than to particular instances (individuals, e.g., this piece of chicken)'; see also Cooper 1975, 30.

${ }^{34}$ E.g. Ross 1924, 117, Cambiano 2012, 21-2 (with further references).

${ }^{35}$ See Cambiano 2012, 22. Devereux 1986, 493-4 seems to be committed to the discrete reading when separates the medical skill as a practical faculty from the medical science as a distinct theoretical faculty and says that the former is self-sufficient: 'The successful practitioner of medicine has both knowledge of universals (the science of medicine) and knowledge of particulars, and the latter is relevant to his being a practitioner but not to his being a scientist. Let us call the combination of the two faculties "medical skill." Now the science of medicine is not a theoretical science since its aim is not simply knowledge; its aim is the restoration or maintenance of health, and it is in this respect practical or productive. It is not "self-sufficient" since it cannot achieve its aim without the help of something else, viz. experience and knowledge of particulars. "Medical skill," on the other hand, is practical both in its aim and in its efficacy in action and it is completely self-sufficient insofar as it needs nothing further to achieve its aim.' Devereux' article is packed with insight, but to separate the practical from the theoretical aspect of the medical techne as two faculties is unfortunate given Aristotle's view of the craft as a single rational dunamis (see particularly Metaph. $\Theta .2$ discussed further below).

${ }^{36} \mathrm{Cf}$. Annas 2011, 120-1: 'if the articulacy requirement [i.e. the requirement of a skill that one be able to give an account of what one is doing] applies only to the learning of practical expertise, and not its expert exercise, then it seems to play no role in bring about the actual expert activity, and we might well wonder whether it should enter into an account of what practical expertise itself is.' Annas in reply points to the way in which expertise allows one to vary one's practice according to circumstances. This point, as I shall argue, is also the key to Aristotle's conception of the practical role of the craftsman's logos.

${ }^{37}$ Cf. e.g. Gregorić and Grgić 2006, 7: 'Although they do not differ as far as production is concerned - in fact, Aristotle observes at 981a21-3, experience without art is more successful in production than art without experience - yet the person informed by art is considered wiser than the person informed only by experience.' 


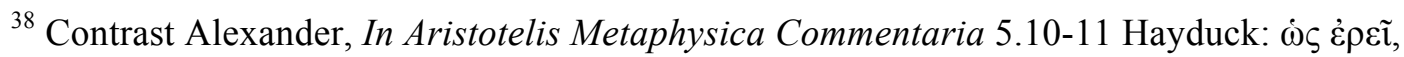

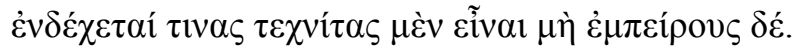

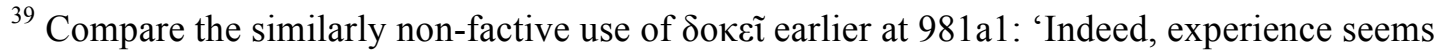
( knowledge in experience and on the fact, which Polus noted, that they both contrast with chance. But the appearance is also corrected by Aristotle when he points out that only craft and knowledge grasp the logos and the universal cause.

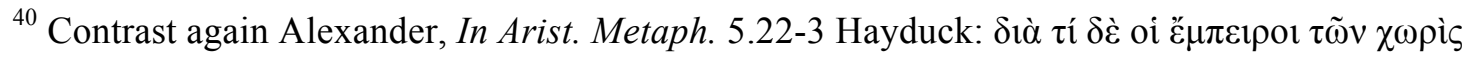

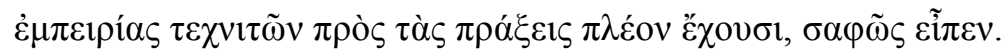

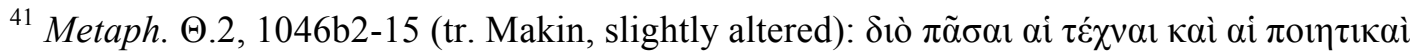

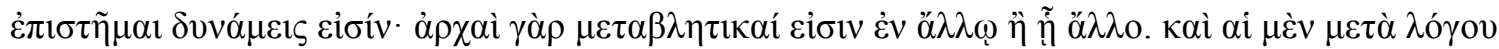

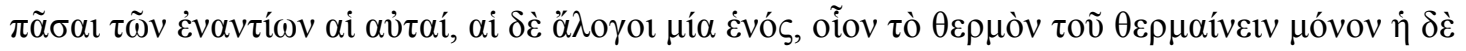

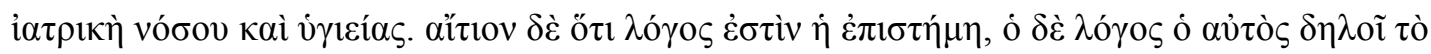

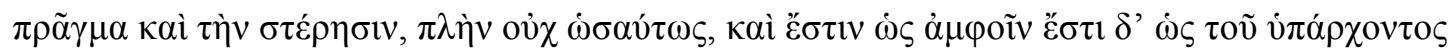

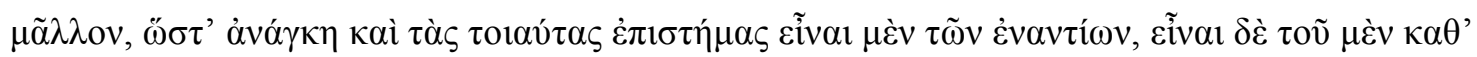

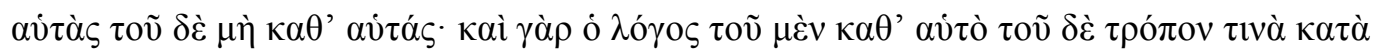

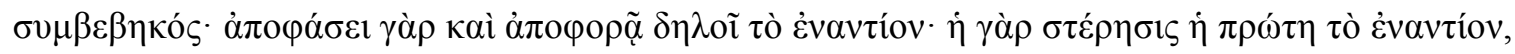

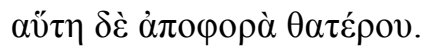

${ }^{42}$ Makin 2006, 48-53 carefully considers possible cases of irrational powers that could have opposite outcomes but concludes that 'if a capacity is non-rational then it is a one-way capacity' (53).

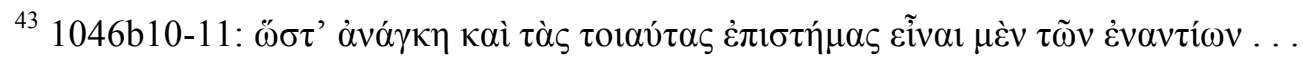

${ }^{44}$ Contrast Bronstein 2012, 48-9, who argues by reference to the role of habit (ethos) in ethical learning that the manual workers too have craft. But even if habit is a necessary condition even for craft, Metaph. $\Theta .5$ shows that it craft presupposes learning (mathēsis). Presumably, such learning corresponds to the teaching referred to in T2, and so is logos-based. For criticism of Bronstein's reading see Hasper and Yurdin 2014, 145 n. 47.

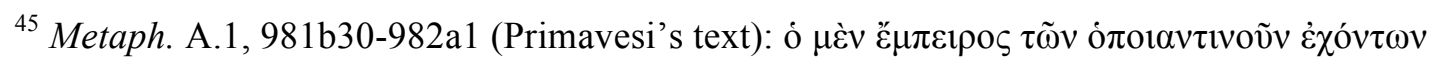

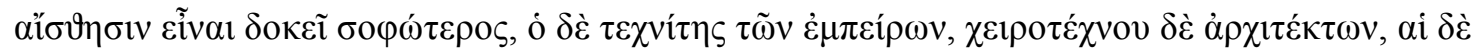

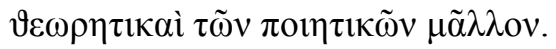


${ }^{46}$ Cf. Generation of Animals 2.1, 734b31-735a2, where Aristotle, comparing the movements of the semen to the instruments of a craftsman, says: 'Exactly the same thing happens with things formed by the processes of the arts. Heat and cold soften and harden the iron, but they do not produce the sword; this is done by the movement of the instruments employed, which contains the logos of the art; since the art is both the principle and form of the thing which is produced' (tr. Peck).

${ }^{47} \mathrm{Cf}$. Cambiano 2012, 22, who talks of the logos as technē's 'theoretical component'; Schiefsky 2005, 352 glosses logos at 981a21 as 'the theoretical knowledge on which the techne is based'; Harper and Yurdin 2014, 139 talk of the novice craftsman's 'inability to apply his theoretical knowledge to particulars'; Angier 2010, 145 goes as far as translating logos as 'theory'.

${ }^{48}$ This, incidentally, is one reason why it is important to mention, as Aristotle does at the beginning of T4, the fact that this sort of capacity occurs in souls that have logos. Such souls are as rational (as having logos) responsive to the craft's logos. When the craftsman is active we can say also that the craft's logos is active in bringing about the product, since the craftsman's soul as rational is such as to realise the craft's logos. It helps, in other words, to explain the causation of the craft's logos to mention that the craftsman's soul is rational and therefore such as to serve as a vehicle for this logos in production.

${ }^{49}$ Already the Hippocratic author worries that medicine should not be approached in too theoretical a manner: 'Certain sophists and physicians say that it is not possible for anyone to know medicine who does not know what man is [and how he was made and how constructed], and that whoever would cure men properly, must learn this in the first place. But this saying rather appertains to philosophy, as Empedocles and certain others have described what man in his origin is, and how he first was made and constructed. But I think whatever such has been said or written by sophist or physician concerning nature has less connection with the art of medicine than with the art of painting. And I think that one cannot know anything certain respecting nature from any other quarter than from medicine; and that this knowledge is to be attained when one comprehends the whole subject of medicine properly, but not until then; and I say that this history shows what man is, by what causes he was made, and other things accurately' (On Ancient Medicine 20). See further the helpful comments in Charles 2002, 153-4.

${ }^{50}$ Frede 2004, 24: 'To begin with, though, we should note that Aristotle in A.1-2 carefully avoids claiming that one does not benefit from theoretical knowledge. He is emphatic that wisdom is not productive, that it does not aim at productive benefit. But this leaves it completely open that one 
may derive productive or practical (in the narrow sense of "moral") benefit from theoretical knowledge. Medicine, according to Aristotle, relies on theoretical knowledge in that it draws on physics. But this theoretical knowledge, from a theoretical point of view either is rather low grade theoretical knowledge or applied knowledge. And in any case, from Aristotle' s point of view, the physician's concern is not theoretical when he studies what we would call "medical theory". Similarly with ethics there is nothing in what Aristotle says which prevents one from availing oneself of theoretical knowledge for moral purposes.'

${ }^{51}$ See Devereux 1986, 497: 'Arts like medicine and rhetoric share with the theoretical sciences the restriction of subject matter to universals, but they are practical in that their aim is not knowledge but what can be done or produced with the knowledge.'

${ }^{52}$ Cf. also Metaphysics Z.7, 1032b5-22. I owe the reference to Jessica Moss.

${ }^{53}$ I am grateful to Jessica Moss and Øyvind Rabbås for help in clarifying this point. See, specifically, Moss 2014, 217 n. 44: 'Bearing in mind the later Metaph. passage on medical deliberation [sc. Z.7 see previous note], however, we can see that formal causes are relevant to craft only insofar as they help connect particular actions to the goal. The doctor needs to know that the cure benefits feverish phlegmatics because that can connect with his understanding of health to show how this cure promotes (is for the sake of) health. The starting-point of productive deliberation is always the statement of a goal ...'

${ }^{54}$ I am grateful to Rachel Barney for raising this objection.

${ }^{55}$ Phys. 2.9, 200a34-b7: "And the end is "that for the sake of which", and the beginning starts from the definition or essence; as in artificial products, since a house is of such-and-such a kind, certain things must necessarily come to be or be there already, or since health is this, these things must necessarily come to be or be there already. Similarly, if man is this, then these; if these, then those. Perhaps the necessary is present also in the definition. For if one defines the operation of sawing as being a certain kind of dividing, then this cannot come about unless the saw has teeth of a certain kind; and these cannot be unless it is of iron. For in the definition too there are some parts that are, as it were, its matter' (revised Oxford transl.).

${ }^{56}$ As Agathon said in T1: 'Craft was fond of fortune, and fortune of craft.'

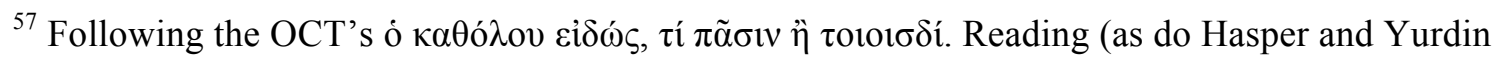

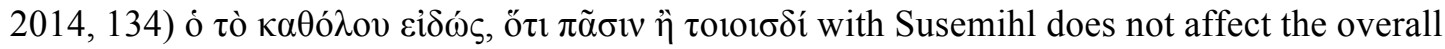


interpretation.

${ }^{58}$ For bile and phlegm as causes of fever, see the Hippocratic Diseases 1.23. For the different causes of too much phlegm and bile, see Diseases 4.35-6. For some of the complications arising from the Hippocratic use of phlegm and bile, see Lonie 1981, 58.

${ }^{59}$ As Moss 2014, 226 rightly observes: 'A doctor who grasps health well enough to recognize how her treatments produce it can presumably treat unfamiliar diseases better than the mere empiric, and a phronimos who grasps the fine well enough to understand how her actions participate in it can presumably handle new situations better than the person with mere experience and habituated emotional responses.'

${ }^{60}$ The examples and the contrast with the real doctor put one in mind of the pseudo-doctor of Plato, Phaedrus 268a-c (tr. Nehamas and Woodruff): '[Socrates:] All right, tell me this. Suppose someone came to your friend Eryximachus or his father Acumenus and said: "I know treatments to raise or lower (whichever I prefer) the temperature of people's bodies; if I decide to, I can make them vomit or make their bowels move, and all sorts of things. On the basis of this knowledge, I claim to be a physician; and I claim to be able to make others physicians as well by imparting it to them." What do you think they would say when they heard that? [Phaedrus:] What could they say? They would ask him if he also knew to whom he should apply such treatments, when, and to what extent? [Socrates:] What if he replied, "I have no idea. My claim is that whoever learns from me will manage to do what you ask on his own"? [Phaedrus:] I think they'd say the man's mad if he thinks he's a doctor just because he read a book or happened to come across a few potions; he knows nothing of the art.'

${ }^{61}$ Cf. the Hippocratic On Ancient Medicine 20 (tr. Chadwick): 'It is my intention to discuss what a man is and how he exists because it seems to me indispensable for a doctor to have made such studies and to be fully acquainted with Nature. He will then understand how the body functions with regard to what is eaten and drunk and what will be the effect of any given measure on any particular organ. It is not enough to say "cheese is harmful because it produces pain if much of it is eaten". One should know what sort of pain, why it is produced and which organ of the body is upset.'

${ }^{62}$ Already Plato, Laws 4, 720b-e had underlined the practical edge that the logos gives the doctor over the empiric (tr. Saunders): “[Athenian:] And these "doctors" (who may be free men or slaves) 
pick up the skill empirically, by watching and obeying their masters; they've no systematic knowledge such as the free doctors have learned for themselves and pass on to their pupils. You'd agree in putting "doctors" into these two categories? [Clinias:] Of course. [Athenian:] ... This kind of doctor never gives any account of the particular illness of the individual slave, or is prepared to listen to one; he simply prescribes what he thinks best in the light of experience, as if he had precise knowledge, and with the self-confidence of a dictator. Then he dashes off on his way to the next slave-patient, and so takes off his master's shoulders some of the work of attending the sick. The visits of the free doctor, by contrast, are mostly concerned with treating the illnesses of free men; his method is to construct an empirical case-history by consulting the invalid and his friends; in this way he himself learns something from the sick and at the same time he gives the individual patient all the instruction he can ... which of the two methods do you think makes a doctor a better healer, or a trainer more efficient?' (latter emphasis mine).

${ }^{63}$ See $A P o$ 1.5, 74a25-32, with relevant discussion at Hasper and Yurdin 2014, 130-3.

${ }^{64}$ One might develop the analogy further by reference to Plato, Meno 97e-98a (tr. Grube): 'To acquire an untied work of Daedalus is not worth much, like acquiring a runaway slave, for it does not remain, but it is worth much if tied down, for his works are very beautiful. What am I thinking of when I say this? True opinions. For true opinions, as long as they remain, are a fine thing and all they do is good, but they are not willing to remain long, and they escape from a man's mind, so that they are not worth much until one ties them down by (giving) an account of the reason why. And that, Meno my friend, is recollection, as we previously agreed. After they are tied down, in the first place they become knowledge, and then they remain in place. That is why knowledge is prized higher than correct opinion, and knowledge differs from correct opinion in being tied down.' Having the logos of the cause allows one to maintain one's true belief in a range of different cases: say when confronted with a confusing or borderline example, or somebody's deceptive counterarguments. See further Moss 2014, 226 n. 57 for a comparison with the Meno. 